\title{
LOS PORTALES VERTICALES DE MARKETING Y PUBLICIDAD EN LOS MEDIOS SOCIALES
}

\author{
Araceli Castelló-Martínez ${ }^{1}$ : Universidad de Alicante. España \\ araceli.castello@ua.es
}

\section{RESUMEN}

El crecimiento experimentado por Internet y, en concreto, las plataformas sociales como espacios para la puesta en marcha de estrategias de marketing, comunicación y publicidad por parte de empresas e instituciones ha venido acompañado por el desarrollo de diversas páginas web con información y contenidos especializados en esta temática. El objetivo del presente artículo se centra en el estudio de los principales portales verticales de marketing y publicidad en España, analizando los contenidos que publican, por una parte, y su presencia en medios sociales, por otra. Se parte de la hipótesis de que las noticias relacionadas con el marketing digital, la publicidad online y los medios sociales son las que más espacio ocupan tanto en la página web como en los espacios en plataformas 2.0 de estos portales. La metodología se basa en la investigación documental de publicaciones de los ámbitos profesional y académico así como en el análisis de case studies de los principales portales verticales de marketing y publicidad. Los resultados destacanla popularidad adquirida por estos portales entre los usuarios de medios sociales, así como la importancia que tienen actualmente en el ámbito del marketing, la comunicación y la publicidad las noticias relacionadas con los medios sociales..

PALABRAS CLAVE: Marketing - Comunicación - Publicidad - Internet - Medios sociales

\footnotetext{
${ }^{1}$ Autor correspondiente

Araceli Castelló-Martínez: Profesora del Departamento de Comunicación y Psicología Social. Universidad de Alicante. Alicante, España.

Correo: araceli.castello@ua.es
} 


\title{
MARKETING AND ADVERTISING VERTICAL PORTALS ON SOCIAL MEDIA
}

\begin{abstract}
The growth of Internet and, in particular, social platforms as spaces for companies and institutions to implement marketing, communication and advertising strategies has been accompanied by the development of various web pages with information and content specializing in this topic. The goal of this article focuses on the study of the major marketing and advertising vertical portals in Spain, analyzing published news, on the one hand, and its presence in social media, on the other. The hypothesis highlights that news related to digital marketing, online advertising and social media are the ones which take more space up on both, websites and spaces in 2.0 platforms of these portals. The method is based on documentary research of both, academic and professional publications, as well as the analysis of case studies of major marketing and advertising vertical portals. The results prove the popularity acquired by these portals between social media users, besides the importance that news related to social media currently has in marketing, communication and advertising field.
\end{abstract}

KEY WORDS: Marketing - Communication - Advertising - Internet - Social media.

\section{INTRODUCCIÓN}

Las empresas están poniendo en marcha cada vez con más frecuencia estrategias de comunicación que tienen lugar en el medio digital, hasta tal punto que las acciones online se han convertido en una parte esencial en la estrategia de comunicación de empresas, instituciones, productos y marcas.

Las nuevas tecnologías y, en concreto, Internet, se han configurado como los medios idóneos para alcanzar el nivel de personalización del mensaje y de interacción con el destinatario necesarios para satisfacer las necesidades y expectativas del cliente actual y potencial, generando así nuevas oportunidades de negocio.

La aparición del medio Internet y el posterior uso intensivo de las Tecnologías de la Información y la Comunicación (TIC) han supuesto cambios en la concepción general de la comunicación, sus elementos constitutivos y modelos explicativos ${ }^{2}$. La sociedad del conocimiento actual está generando, cada vez más, una mayor conectividad por parte del público al que se dirigen las comunicaciones corporativas. De ahí que la comunicación digital, para ser eficaz y cumplir los objetivos previamente definidos,

\footnotetext{
2 Bryant y Miron (2004, p. 697) concluyen en su estudio que ninguna de las teorías de la comunicación de masas más populares del siglo XX parece "particularmente preparada para explicar, predecir o ni siquiera servir a los grandes cambios que se están produciendo en nuestras instituciones mediáticas, en el sistema de mensajes y audiencias".
} 
haya de ser participativa e interactiva, con el fin de de generar y aportar valor añadido al cliente actual y/o potencial y crear vínculos emocionales entre la marca/empresa y los usuarios.

La Red es hoy en día uno de los canales fundamentales en la interacción y la comunicación de personas, empresas e instituciones. De acuerdo con el resumen general de 2011 del "Estudio General de Medios" (febrero-noviembre) publicado por la Asociación para la Investigación de Medios de Comunicación (AIMC) ${ }^{3}$, la audiencia mensual de Internet asciende al 58,5\% de la población española de 14 años o más y el 73\% de los internautas accede a la Red a diario.

La inversión publicitaria en medios interactivos ha vivido en los últimos años un crecimiento muy rápido: Internet $(13,5 \%)$ es el tercer medio en el reparto de la inversión publicitaria en medios convencionales en España, según el "Estudio InfoAdex de la inversión publicitaria en España 2011" publicado por InfoAdex ${ }^{4}$ con 789,54 millones de euros, y de enero a septiembre de 2011 la inversión publicitaria en Internet creció un 8,5\% con respecto a los nueve primeros meses de $2010^{5}$.

Internet se consolida así como el medio más consumido por los españoles, de tal manera que la industria y el sector publicitario son hoy más online que nunca, como señala Madinabeitia (2010, p. 43) al afirmar que "la digitalización de la sociedad ha traído consigo grandes cambios en todos los ámbitos, siendo el mundo de la comunicación y en concreto el de la comunicación comercial uno de los más afectados". Las principales ventajas de Internet como medio de comunicación y soporte de comunicación empresarial, que hacen del medio online un canal cuanto menos necesario en los planes estratégicos de los anunciantes, son:

a)

Alta capacidad de afinidad

b) y microsegmentación.

elevada penetración en la población.

c)

Amplia cobertura, por su

comunicación directa con clientes actuales y potenciales.

d) Evaluación y optimización del retorno de la inversión (ROI) en tiempo real y exhaustiva medición post-campaña.

e)

Acceso a un potencial consumidor muy cualificado, exigente y proactivo (prosumer), gracias a toda la información que tiene a su alcance en el espacio digital, y que cada vez más practica el multitasking 5 .

f) recuerdo y branding con costes reducidos. 

g)
fidelización.
h)
en torno a la marca (engagement).
i)
otros medios, demostrada por los estudios cross media.
Canal de venta $y$
Creación de comunidades
j)
variedad de formatos, soportes, modelos de negocio, etc.
Complementariedad con
Flexibilidad y amplia

Es fundamental que las empresas sean conscientes de la necesidad de adaptar sus estrategias de comunicación empresarial y publicitaria a las peculiaridades de las plataformas digitales de manera profesional para aprovechar al máximo sus potencialidades y de llevar a cabo una comunicación integral e integrada entre acciones online y offline. Internet debe formar parte de la Integrated Communication Strategy (Victoria, 2005, p. 51), que lleva a la empresa a afrontar su labor comunicativa desde una visión global y holística.

El consumidor social cada vez toma más decisiones de compra y consumo basándose en opiniones, experiencias y comentarios que comparte con otros usuarios en entornos colaborativos como Facebook y busca en estas plataformas descuentos, promociones y ofertas. Este nuevo escenario ha obligado a una redefinición de los planteamientos teóricos y prácticos del marketing, la comunicación y la publicidad, ámbitos que se han convertido en la Red en populares temas de información y conversación gracias al interés de empresas e instituciones por estar en los medios sociales.

En este artículo estudiaremos los contenidos y la presencia en plataformas sociales de las principales páginas web con contenidos de marketing y publicidad. Con el fin de contextualizarlo, en el marco teórico se repasa la estrategia de marketing, comunicación y publicidad digitales y se revisan las peculiaridades de la Web 2.0 y los medios sociales, como fenómenos que han motivado el desarrollo de estos portales verticales gracias a su uso como espacios para las estrategias empresariales.

\subsection{La estrategia de marketing, comunicación y publicidad digitales}

En 2007 la publicación Advertising Age avecinaba que "las fronteras del marketing entre los formatos digitales y los tradicionales se difuminarán definitivamente a lo largo de los próximos 5 años". Es lo que autores como Alonso Coto (2008) llaman blended marketing, al defender que el plan de marketing actual es digital, al integrar las nuevas posibilidades de las herramientas online con formatos y medios tradicionales, combinación que refuerza los valores de marca. Para Alonso Coto (2008, p. 5):

Es clave integrar estas nuevas posibilidades de marketing digital con los formatos y medios que llevan años demostrando su eficacia. De hecho, el uso 
combinado de herramientas online y offline en una misma campaña de marketing, potencia el recuerdo de los valores de marca en hasta un $18 \%$, lo que refrenda a Internet como un medio muy rentable e inexcusable pero en ningún caso exclusivo para toda campaña de marketing, comunicación y publicidad.

PRECIO

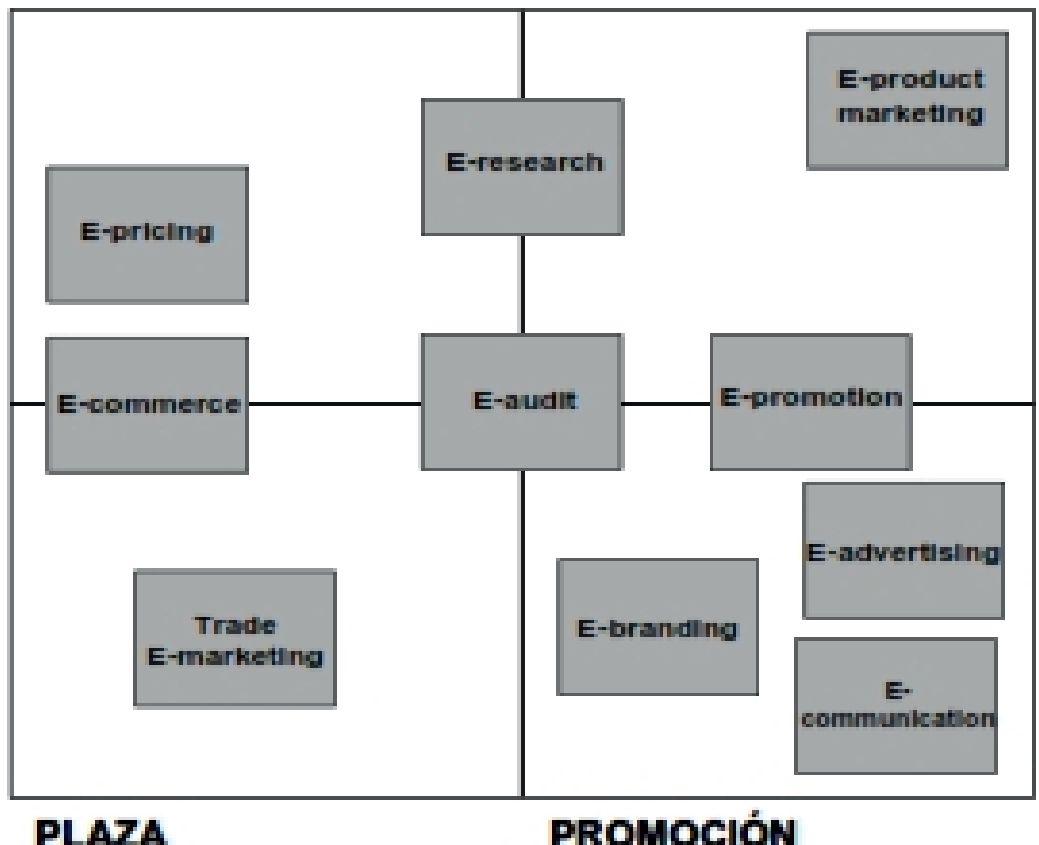

Figura 1. Herramientas de marketing digital en Web 2.0

Fuente: Elaboración propia a partir de Alonso Coto, 2008, p. 182

Según Fleming (2000, pp. 55 y ss.), el marketing online se caracteriza por las 4 F's

a) que entra un cibernauta si hay bastantes oportunidades de interactividad y un alto interés en la información.

b) presentación e integración de posibilidades audiovisuales o gráficas, contar con una homepage atractiva, clara y útil para que el usuario pueda ser captado.

c) servicio personal proporcionado al usuario y la capacidad de establecer un diálogo con los usuarios. 
d)

Fidelización: una vez captado un usuario, lograr conservarlo y recordarle que es especial y único mediante comunicaciones personalizadas.

Para el autor Celaya (2008, pp. 84-88), existen varios factores que han transformado el modelo de comunicación digital del 1.0 al 2.0:

a)

Incremento de clientes más

inteligentes, formados y exigentes.

b) comerciales, con sobreabundancia de información y congestión publicitaria.

c) Nuevos líderes de opinión. La democratización de la comunicación, la inmediatez en la difusión del mensaje y la fusión de los roles emisor-receptor hacen que cualquiera pueda ser emisor de mensajes y, por tanto, convertirse en prescriptor, como los bloggers.

d)

los medios tradicionales.

e)

Pérdida de credibilidad de

Clientes en red. Las nuevas tecnologías han desarrollado la creación de múltiples comunidades con los mismos gustos, tendencias u opiniones. Las empresas deben tener en cuenta este alto grado de interconexión entre clientes actuales y potenciales.

Scolari (2008, p. 78) sintetiza las particularidades de las nuevas formas de comunicación frente a las tradicionales en la transformación tecnológica (digitalización), la configuración muchos-a-muchos (reticularidad), las estructuras textuales no secuenciales (hipertextualidad), la convergencia de medios y lenguajes (multimedialidad) y la participación activa de los usuarios (interactividad). Además, destaca que la interactividad de los medios digitales genera una ruptura de las categorías que fundaban el proceso cultural (producción-emisor y consumoreceptor): "al participar en el control de los contenidos, el usuario de los medios interactivos termina por convertirse en parte de ese contenido. Parafraseando a Mcluhan, podría decirse que en las nuevas formas de comunicación digital el usuario es el mensaje" (2008, p. 98).

De Salas (2002, p. 72) se pregunta cómo ha transformado Internet la comunicación empresarial e institucional, a lo que responde:

Debido a la incorporación de la tecnología multimedia interactiva, la corriente o flujo informativo entre la empresa y sus posibles públicos se modifica. Los dos modos clásicos en que las empresas emiten los mensajes dirigidos a sus clientes y público externo (pull y push) toman valores y caminos diferentes. A nivel genérico, podríamos decir que la empresa pierde protagonismo en las relaciones comerciales en detrimento del consumidor. Éste, a su vez, y gracias a las nuevas tecnologías, puede desarrollar una actividad más activa en la 
búsqueda y análisis de información, así como en todos los procesos de la relación mercantil que desarrolla con la empresa. Por lo tanto, las actividades comerciales apoyadas en las nuevas tecnologías, permiten y fomentan la mayor participación del sujeto consumido.

El amplio abanico de acciones a disposición del anunciante que ofrece el medio online, así como de soportes, formatos y formas de negociación/contratación, hacen que en muchas ocasiones las estrategias de presencia publicitaria digital se centren en targets hipersegmentados, en nichos de mercado definidos en base a técnicas como el behavioural targeting "que conforman una "larga cola" (long tail)7 de públicos específicos a los que hacer llegar el mensaje del anunciante.

Algunas de las acciones que pueden configurar una estrategia de comunicación digital y que son las más empleadas por la empresa actualmente son el website, el posicionamiento natural (SEO), la publicidad online (displays, SEM, e-mail marketing y marketing de afiliación), los medios sociales, el comercio electrónico y el social commerce o el mobile marketing y la geolocalización.

Es importante no olvidar la importancia que tiene el sitio web de una compañía, como espacio en torno al cual giran el resto de acciones de comunicación digital y al que la mayoría de ellas redirigirán como página de destino con el fin de generar tráfico. En este sentido, una característica que debe guiar todo el proceso de diseño y configuración de un website es la usabilidad, que se refiere a la capacidad de uso y facilidad de navegación de un sitio web. Es importante que la página web de la empresa cuente con una interfaz que facilite la navegación, una buena estructura de contenidos y una composición congruente, que permita una lectura creativa y fácil, a la vez que interactiva.

SEO (Search Engine Optimization) se refiere al posicionamiento orgánico de una página en los resultados naturales en respuesta a la búsqueda realizada por un usuario. El lugar en el que aparece la página viene determinado por el grado de optimización del sitio web. El proceso de optimización SEO requiere un análisis constante de los algoritmos de los buscadores, conocimientos de redacción para la web, conocimientos de navegación, arquitectura de la información, diseño y marketing

\footnotetext{
${ }^{6}$ En Internet, el behavioural targeting es un modelo de publicidad basado en identificar los sitios web por los que navega el usuario y el tipo de comportamiento que realiza en la navegación entre sitios, permitiendo al anunciante escoger los perfiles de usuarios más afines. Esta disciplina se basa en la posibilidad, mediante el uso de datos anónimos, de servir al internauta un determinado contenido, bien sea publicitario o editorial, como respuesta a su comportamiento de navegación (sitios web consultados, palabras clave introducidas en los buscadores, comportamiento de compra online, etc.).

7 Expresión acuñada por Chris Anderson en un artículo en la revista Wired en octubre de 2004 para describir aquellos tipos de negocios y modelos económicos generados por el entorno digital, gracias a la reducción del coste de almacenamiento y distribución, que permite que ya no sea necesario focalizar el negocio en pocos productos o en un mercado de masas, dando lugar a nichos de mercado, que configuran la larga cola
} 
Con respecto a la publicidad online, según el "Estudio sobre inversión publicitaria en medios digitales" 8 de Interactive Advertising Bureau Spain (IAB Spain) con los resultados del año 2010, el 52,8\% de la inversión en medios digitales corresponde a search (enlaces patrocinados) y el $47,2 \%$ a gráfica (displays). Dentro de los displays, el 60,3\% de la inversión corresponde a Coste Por Mil Impresiones (CPM) como modelo de precio, seguido por Coste por Resultados $(15,1 \%)$, tiempo fijo (14,3\%) y Coste por Click (CPC), con un $8 \%{ }^{9}$. Atendiendo a la distribución de la inversión por formatos, los integrados son los más populares (megabanner, rascacielos, robapáginas, etc.), con un $51,4 \%$, seguidos por patrocinios y secciones fijas (9\%) y el e-mail $(7,8 \%)$.

En general, en el proceso de elaboración de un plan de medios online con displays se toman una serie de decisiones relacionadas con la selección de soportes, formatos y forma de negociación/contratación, en base a los objetivos del anunciante.

Desde el punto de vista de la planificación publicitaria, los criterios que pueden emplearse para seleccionar soportes son la afinidad de perfiles y contenidos (capacidad de segmentación), la cobertura y la frecuencia, la rentabilidad (tarifas, descuentos y retorno de la inversión) y valores añadidos como el asesoramiento o la investigación de mercado. Los soportes publicitarios online más utilizados en la planificación publicitaria de displays son las webs corporativas, los portales horizontales y verticales ${ }^{10}$, las redes exclusivistas ${ }^{11}$ o los sitios de otros soportes offline como la prensa o la radio.

SEM (Search Engine Marketing) implica que el anunciante paga por aparecer en un lugar destacado en los resultados de búsqueda (habitualmente en primeros resultados y columna de la derecha), indicado como publicidad. La promoción en buscadores (SEM) presenta dos opciones publicitarias: los enlaces patrocinados mostrados como respuesta a una búsqueda activa del usuario y la publicidad contextual, enlaces patrocinados en sitios web que tengan una temática afín a la de los productos o servicios publicitados o se adecuen al perfil del internauta.

\footnotetext{
${ }^{8}$ Disponible en: http:/ / www.iabspain.net/ver.php?mod=descargas\&id_categoria $=4,14,40,17$

${ }_{9}^{9}$ Coste por Mil Impresiones (CPM) es un modelo de negocio basado en la exposición que indica el precio fijado por cada 1000 veces que la pieza publicitaria se carga en una página web como consecuencia de la solicitud de la misma por parte de un usuario en su recorrido de navegación, sin que necesariamente tengan que ser 1000 usuarios diferentes. Coste por resultados indica el pago de acuerdo al número de aquello que se persiga (ventas, suscripciones a la base de datos, solicitudes de información, etc.). Coste por Click (CPC) es un modelo basado en resultados (clicks), en el que el anunciante remunera al soporte en función del número de clicks generados por los formatos. Se trata del precio fijado por cada vez que un usuario pincha en la pieza publicitaria para dirigirse a la página web de destino

${ }^{10}$ En sus inicios se conocía como portal la página web utilizada por el internauta para acceder a Internet y desde ella a los diversos recursos existentes en la Red. Los portales horizontales (MSN.ES, Yahoo.es, Orange.es) son páginas web que aglutinan información de temáticas diversas, mientras que los portales verticales son páginas web con contenidos específicos de alguna temática concreta (automoción, moda, finanzas, etc.).

11 Empresas que gestionan y comercializan el espacio publicitario de varias páginas web de diverso contenido y que suelen agrupar en paquetes temáticos o en función del perfil del usuario
} 
El e-mail marketing consiste en la creación de piezas publicitarias que se envían al usuario a través del correo electrónico. De acuerdo con el "Libro Blanco del E-mail Marketing" desarrollado por IAB Spain ${ }^{12}$, esta técnica se suele utilizar con dos finalidades: captación de nuevos clientes mediante la compra de bases de datos externas y retención de clientes ya adquiridos mediante programas de fidelización. En el e-mail marketing es importante haber recibido el consentimiento por parte del usuario par recibir mensajes comerciales a través del correo electrónico, procedimiento conocido como opt-in.

La afiliación es un acuerdo entre dos sitios web, en el que el afiliado acepta poner un contenido o anuncio para dirigir tráfico a otro website. Como compensación, el afiliado recibe un porcentaje de las ventas, un coste por registro o por visita como forma de compensación por generar tráfico o ventas. La función de las compañías que ofrecen servicios de marketing de resultados a través de programas de afiliación es coordinar los intereses entre oferta y demanda. El objetivo de la red de afiliación es conseguir un alto número de webs de calidad y anunciantes interesados, creando una relación win-to-win. El pago en las redes de afiliación siempre es por resultados (visita, registro, venta, suscripción, etc.).

La saturación publicitaria y la profesionalización de los hábitos de navegación del usuario han motivado que cada vez más los esfuerzos de los anunciantes se centren en espacios en los que la marca y el producto se integran con el contenido y, más allá, la marca crea su propio contenido para compartirlo con los usuarios (brand content), como sucede en los medios sociales.

Plataformas 2.0 como Facebook o Twitter han hecho que el rango de posibilidades que ofrece Internet como soporte publicitario se multiplique, sobre todo gracias a espacios en los que el cliente forma parte de la comunidad de la marca y conversa con la empresa anunciante, en contraposición con la unidireccionalidad que tradicionalmente ha caracterizado a los medios convencionales como canales publicitarios.

El informe "Marketing en medios sociales" publicado por Territorio Creativo en abril de 2010 destaca que ocho de cada diez empresas que llevan a cabo acciones de Social Media Marketing (SMM) aprueban la eficacia de los medios sociales para generar notoriedad de marca ${ }^{13}$. Como ejemplo, en Facebook, la empresa tiene un amplio abanico de posibilidades comunicativas: página corporativa, aplicaciones, anuncios sociales, historias patrocinadas, promociones y concursos, eventos, f-commerce y Facebook places.

\footnotetext{
12 Puede consultarse en http:/ / www.iabspain.net/ver.php?mod=descargas\&id_categoria=9

${ }^{13}$ Estudio completo disponible en:

http://dl.dropbox.com/u/4905692/TC_Estudio_encuestaSMM_abril2010.pdf
} 
Por comercio electrónico se entiende toda compra realizada a través de Internet, cualquiera que sea el medio de pago utilizado. La característica básica del comercio electrónico reside en la orden de compraventa, la cual tiene que realizarse a través de algún medio electrónico, con independencia del mecanismo de pago efectivo.

Algunas de las ventajas del comercio electrónico para la empresa son el ahorro en costes derivado de la simplificación de tareas, la flexibilidad y velocidad en los procesos, el alcance global y el acceso directo al consumidor. Por su parte, para el consumidor comprar online supone comodidad de acceso, amplitud de contenidos e información más detallada, ahorro de tiempo, acceso a ofertas, promociones y productos exclusivos y búsqueda y comparativa más precisas, entre otras ventajas.

En cuanto a la tipología de sitios de comercio electrónico, hay diferentes tipos de venta online $\mathrm{y}$, por lo tanto, distintos comportamientos por parte de los consumidores. Podemos hablar de cuatro tipos: ventas grupales, caracterizadas por los cupones descuento, ventas en outlet de productos exclusivos o de marca, agregadores de ofertas y el comercio electrónico propiamente dicho, con la venta de los mismos productos de la tienda física en un espacio virtual.

La explosión de plataformas en Internet al servicio del marketing y la comunicación empresarial, derivadas de los espacios de la Web 2.0 y fundamentalmente basadas en la integración de contenidos, ha hecho que entornos colaborativos como Facebook y Twitter también se empleen como un nuevo canal de venta y atención al cliente, teniendo en cuenta el papel que juega la influencia social en el comportamiento de compra y consumo del usuario así como el espacio de conversación, sobre temáticas como las marcas, que representan hoy en día las redes sociales.

La filosofía del social commerce sigue siendo la de las plataformas 2.0 que desarrollaremos en el siguiente punto: escuchar a los usuarios y conseguir generar interacción por parte de ellos, para fortalecer el vínculo con el consumidor y, de esta manera, crear una oportunidad de negocio y de fidelización del cliente. El punto fuerte para la venta online de estos entornos colaborativos es la conversación y recomendación que se genera entre los usuarios a propósito de productos y marcas, para comparar precios, comentar usos, resolver dudas, dar consejos de instalación, etc. Además, la conversación tiene lugar en todo el proceso: antes, durante y después de la compra.

Por último, la alta penetración que tiene el acceso a Internet a través del móvil ha hecho que la inversión del anunciante en acciones de mobile marketing crezca hasta llegar a los 9,3 millones de euros en $2010^{14}$. Las opciones del marketing móvil se han

\footnotetext{
14 Dato de IAB Spain y Mobile Marketing Association Spain (MMA Spain). Para más información sobre la situación de mobile marketing puede consultarse el "III Estudio IAB Spain sobre mobile marketing: percepciones del usuario y estrategias del sector publicitario", publicado en noviembre de 2011 y disponible en:

http://www.slideshare.net/IAB_Spain/iii-estudio-iab-spain- sobre-mobile-marketing?player=js
} 
multiplicado gracias a la geolocalización, sistema por el cual la ubicación geográfica se puede comunicar a través de dispositivos móviles, de tal manera que se asigna una coordenada geográfica a la información para explotarla desde una herramienta informática. Los más comunes son Foursquare o Facebook Places.

La selección de un mix de acciones online como las que hemos repasado para la elaboración del plan de comunicación y publicidad digital dependerá de los objetivos marcados por la empresa en el briefing, de las particularidades de la empresa/producto a comunicar, como por ejemplo su posicionamiento, y del público destinatario de la comunicación, entre otros.

En general, tres suelen ser los objetivos prácticamente presentes en cualquier plan de comunicación digital: generar notoriedad y tráfico a la web, lograr conversiones a objetivos de marketing y construir relaciones duraderas con clientes y fans (fidelizar).

\subsection{La Web 2.0 y los medios sociales}

El receptor se ha convertido en el eje de los procesos comunicativos de la empresa a través de plataformas digitales, dadas sus capacidades de participación e interacción. La Web 2.0 alude a la Red como un espacio social y se enmarca dentro de la teoría de la comunicación digital interactiva, caracterizada por las hipermediaciones (Scolari, 2008, pp. 113-114).

Espacios como los blogs o las redes sociales han permitido al usuario pasar de ser mero consumidor pasivo de contenidos a generarlos (User Generated Content), editarlos en base a sus intereses y compartirlos con su comunidad: "el receptor además de audiencia, de público y de consumidor, deviene usuario y prosumer, es decir, co-productor, distribuidor y consumidor, todo al mismo tiempo" (Bermejo, 2008, p. 49). Términos como crossumer, prosumer, fansumer o persumer destacan la "dimensión interactiva del usuario" (Marshall, 2004, p. 51), que ha modificado el concepto de audiencia en entornos colaborativos y tecnologías participativas.

Desde el lado de la empresa, escuchar y relacionarse con los clientes a través de las comunidades de la marca en estos nuevos espacios, buscando generar el engagement, supone una transformación total de la cultura y la comunicación corporativas, al integrar precisamente en el centro del proceso al consumidor, actual y/o potencial, según la filosofía 2.0. Afirma Martí Parreño (2006, p. 6) que:

Los mensajes están siendo sustituidos por 'contextos de comunicación' en torno a las marcas con los que atraer e interesar a un nuevo tipo de consumidor más crítico y formado en medios y contenidos que participa de forma interactiva y proactiva en estos procesos de comunicación de las marcas 
Se pasa, así de una economía de mercado a una economía de las relaciones. Como ya predijo el Manifiesto Cluetrain al afirmar que "los mercados son conversaciones" 15 , los medios sociales permiten a las empresas participar en conversaciones y aportar contenido de interés para los usuarios, en un entorno favorable tanto para consumidores como para marcas. Apunta Madinabeitia (2010, p. 49) que:

\begin{abstract}
Ahora la mayor parte de los especialistas reconocen que tan importante como el papel persuasor de la publicidad es su capacidad de 'generar conversaciones'. El consumidor ocupa ahora, de verdad, el centro de todo el sistema. Este hecho ha implicado un cambio radical en la comunicación comercial.
\end{abstract}

La consolidación de las redes sociales como modelo de comunicación masiva ha hecho que estas plataformas crezcan cada día en usuarios de manera exponencial; según datos de ComScore, a finales de 2011 Facebook supera los 800 millones de usuarios.

En España, de acuerdo con la edición de 2011 del estudio anual "Navegantes en la Red" publicado por la AIMC, las redes sociales son un fenómeno en continuo ascenso: un $60,3 \%$ de la población internauta se conecta a ellas diariamente, frente al $43,5 \%$ que lo hacía en 2009 y el 28,6\% que accedía diariamente en 2008. Facebook es la

red social más popular en España, con más de 15 millones de usuarios, al conectarse a ella el $90 \%$ de los usuarios de redes sociales, seguida de Tuenti y Twitter. En el caso de esta última, destaca el crecimiento experimentado de 2009 a 2010, de 12,7\% a $21,9 \% 16$

Las redes sociales son los espacios que ocupan un mayor porcentaje de tiempo de consumo de Internet de los usuarios españoles, según un estudio llevado a cabo por Nielsen Online. El 70\% de internautas fueron usuarios de redes sociales en 2010, frente al 51\% que lo era en 2009, de acuerdo con el "II Estudio sobre redes sociales en Internet" de IAB Spain y Elogia Ipsofacto ${ }^{17}$.

En el ámbito de la comunicación comercial, varios estudios han demostrado que las marcas se han convertido en un actor más en el tejido de las relaciones: alrededor de la mitad de los usuarios de la Red declaran unirse y seguir actividades de marcas, Facebook es considerado un canal de referencia a la hora de buscar información de una marca y el 16\% de los usuarios de Facebook conecta con nuevos usuarios a través de la interacción con las marcas, el 51\% en el caso de los usuarios de Twitter.

\footnotetext{
15 Puede consultarse en:

http://www.well-comm.es/wellcommunity/wp-content/uploads/cluetrain.pdf

${ }^{16}$ Estudio disponible en: http:// www.aimc.es/-Navegantes-en-la-Red-.html
} 
Además, al haber pasado a formar parte de una comunidad de marca, los usuarios tienen una visión más positiva de ella, reconocen tener más probabilidad de comprar la marca, se siente más fiel a ella e invitan a otros usuarios a unirse a la comunidad ${ }^{17}$.

Por tanto, los usuarios conversamos sobre marcas en los medios sociales, actividad todavía más intensa si nos fijamos en el público joven, que es quien pasa más tiempo en estas plataformas y, por tanto, quien más recomendaciones, críticas y sugerencias acerca de empresas y productos intercambia, como demuestra el estudio "Urban Legends: Word-of-mouth myths", de Colloquy:

Tabla 1. Métodos de comunicación empleados para hablar sobre productos. Comparativa entre jóvenes (18-25 años) y la población general estadounidense 18

\begin{tabular}{|c|c|c|}
\hline & Jóvenes (18- & Población \\
\hline Conversaciones cara a cara & $77 \%$ & $84 \%$ \\
\hline Correo electrónico & $50 \%$ & $58 \%$ \\
\hline Teléfono fijo & $36 \%$ & $53 \%$ \\
\hline Conversaciones a través de teléfono móvil & $70 \%$ & $50 \%$ \\
\hline Redes sociales & $56 \%$ & $35 \%$ \\
\hline Chat & $36 \%$ & $22 \%$ \\
\hline Mensajes en teléfono móvil (SMS) & $48 \%$ & $19 \%$ \\
\hline Página web de la empresa & $18 \%$ & $17 \%$ \\
\hline Comentarios sobre el producto/servicio en páginas & $18 \%$ & $17 \%$ \\
\hline Páginas web personales / blogs & $19 \%$ & $14 \%$ \\
\hline Microblogs (por ejemplo, Twitter) & $12 \%$ & $5 \%$ \\
\hline
\end{tabular}

En definitiva, la presencia de empresas y marcas en los nuevos entornos digitales es una realidad motivada por las bondades de las plataformas sociales en el ámbito del marketing y la comunicación empresarial, gracias a las posibilidades de orientación empresarial basada en las relaciones (la filosofía del client first), generación de branding social, segmentación y personalización de mensajes, evangelización a través de la prescripción y la viralidad y la puesta en marcha de un experiential marketing que genere customer engagement ${ }^{19}$

\footnotetext{
${ }^{17}$ Resultados de la segunda oleada del estudio "Observatorio de Redes Sociales", realizado por The Cocktail Analysis, publicado en febrero de 2010 y disponible en http://www.slideshare.net/TCAnalysis/tca-2ola-observatorio-redes-informe- pblicov2-2, y del informe "Wave 5. The socialisation of Brands", de Universal McCann, que puede consultarse en http://www.slideshare.net/Olivier.mermet/universal-mccann-wave-5-the-socialisation-of-brands

${ }_{18}$ Estudio publicado en diciembre de 2010 y disponible en http://www.colloquy.com/files/2011COLLOQUY-Talk-Talk- White-Paper.pdf

${ }_{19}$ Para una información más detallada sobre estas ventajas, puede consultarse Castelló, 2010, pp. 79-98.
} 
Como destaca el estudio "Turning 'like' to 'buy'. Social media emerge as a commerce channel”, de Booz \& Company, la integración de los medios sociales en la estrategia de marketing permite aplicar estas plataformas en cada uno de los objetivos ${ }^{20}$ :

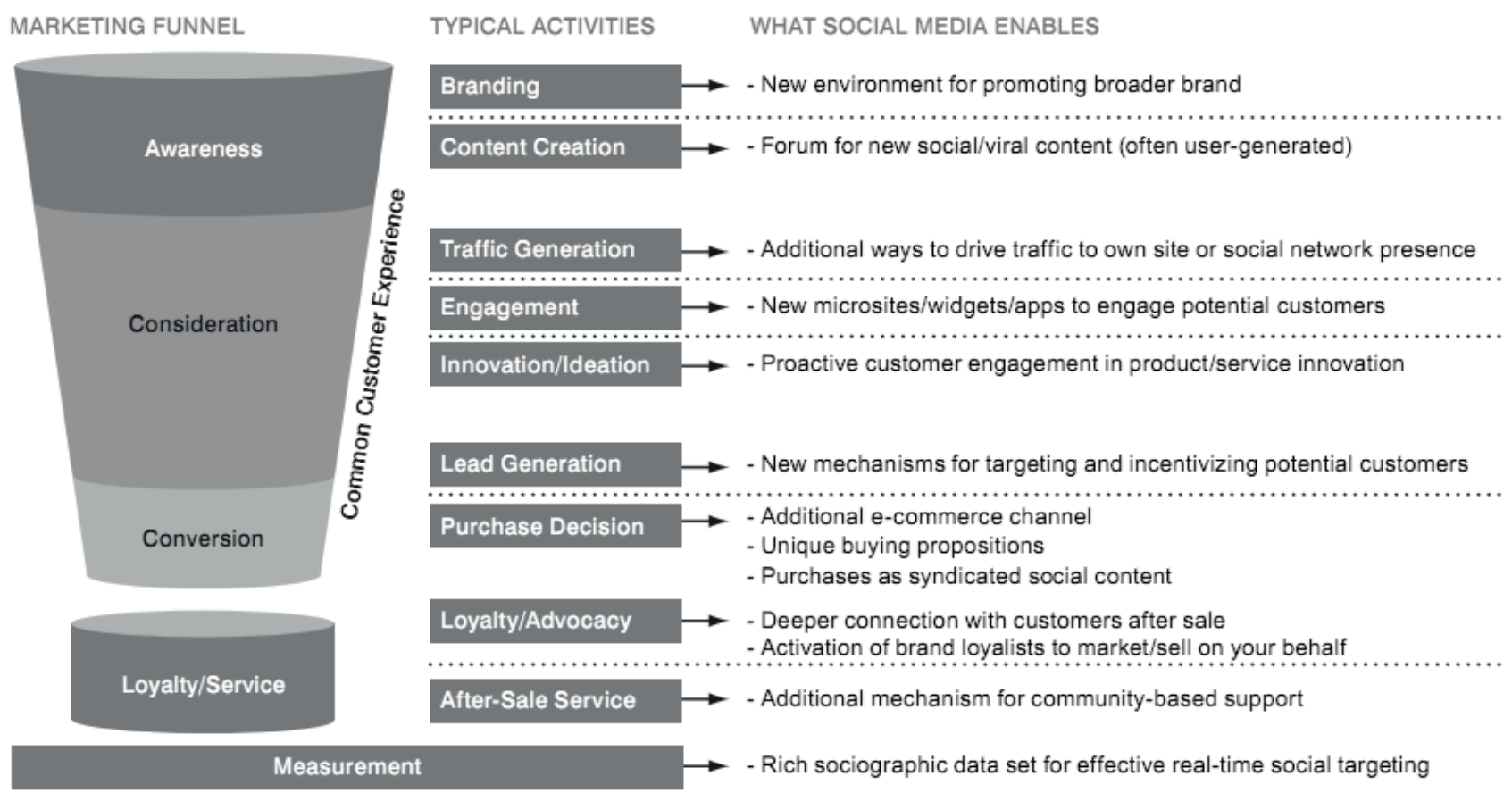

Figura 2. Actividades de marketing en medios sociales

En las plataformas 2.0, es fundamental que la empresa monitorice lo que se dice de ella en tiempo real, escuche activamente, participe en conversaciones con un lenguaje próximo y cercano, ofrezca actualizaciones frecuentes con contenidos relevantes y de calidad, responda de manera rápida y transmita transparencia y confianza.

Sin embargo, muchos estudios demuestran que la respuesta dada por la empresa al usuario es escasa, pese a las potencialidades de estas plataformas, más si cabe cuando se trata de dar respuesta a quejas. De acuerdo con Social Bakers, las páginas de marcas en Facebook no responden al 95\% de los comentarios. El estudio "Social Media y Customer Feedback", realizado por Market Tools, destaca que tan sólo un $25 \%$ de las empresas presentes en Facebook afirma responder siempre a las quejas de los clientes en redes sociales; el 17\% reconoce no haber respondido nunca o haberlo hecho muy pocas veces:

\footnotetext{
${ }^{20}$ Puede consultarse en http://www.booz.com/media/uploads/BaC-Turning_Like_to_Buy.pdf
} 

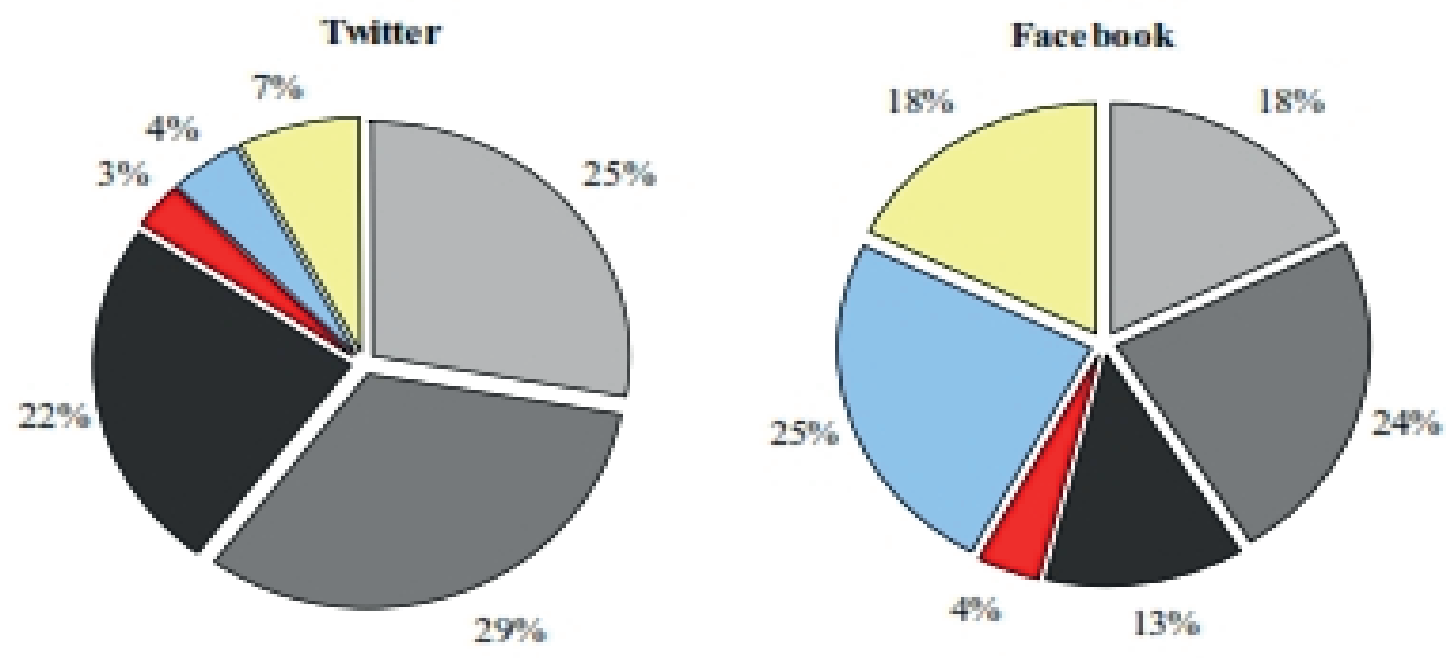

$\square$ Siempre $\square$ A menudo $\square$ Algunas veces $\square$ Raras veces $\square$ Nunca $\square$ No sabe / no contesta

Figura 3. Frecuencia de respuesta en Facebook y Twitter a comentarios de usuarios

\section{METODOLOGÍA}

La investigación documental de publicaciones de los ámbitos profesional y académico relacionadas con las palabras clave de la presente comunicación nos ha permitido localizar la información ya publicada sobre el tema de estudio, establecer un marco de referencia al fenómeno objeto de la investigación y analizar los estudios e investigaciones realizados sobre la materia. Fruto de esta investigación documental, en el marco teórico se han repasado las peculiaridades de la estrategia de marketing, comunicación y publicidad aplicada al ámbito digital así como el uso de plataformas con una filosofía 2.0 dentro de la misma.

El objetivo del trabajo de campo se centra en el estudio de los principales portales verticales de marketing y publicidad en España, como espacios que se hacen eco de las tendencias actuales en el ámbito del presente artículo, analizando los contenidos que publican, por una parte, y su presencia en medios sociales, por otra. Junto con la investigación documental, la metodología se basa en el análisis de case studies de los principales portales verticales de marketing y publicidad. Para la selección de estas páginas web se utiliza como referencia:

a)

El ranking para la categoría de portales verticales de marketing, comunicación y publicidad de la empresa de medición de audiencia digital ComScore ${ }^{21}$.

\footnotetext{
${ }^{21}$ En noviembre de 2011 la empresa ComScore se proclamaba ganadora del concurso que la Mesa de Contratación Digital, coliderada por AIMC e IAB Spain, había convocado para adjudicar la contratación del sistema de medición online en España a aquella metodología que mejor se adaptara a las necesidades del mercado. Puede leerse la noticia en: http://www.abc.es/20111027/medios-redes/abciaudiencia-digital-comscore-201110271129.html
} 
b)

Los resultados del buscador Google para cada portal y para las palabras clave "noticias marketing", "noticias comunicación" y "noticias publicidad".

c)

El informe del medidor internacional de visitas a web gratuito Alexa (alexa.com).

d)

El pagerank de las páginas web. Se trata de un valor numérico que representa la importancia que una página web tiene en Internet y que determina la posición que va a tener una página dentro de los resultados de búsqueda, en base a la calidad de los enlaces que una web recibe de otras, la relevancia de estas páginas que enlazan, las palabras clave que éstas usan para redirigir y las palabras clave del propio site, entre otras. Puede calcularse en calcularpagerank.net.

De acuerdo con el ranking de ComScore, los principales portales verticales de marketing, comunicación y publicidad son MarketingDirecto.com, Puromarketing.com, Anuncios.com y Marketingnews.es. MarketingDirecto.com es líder con 135.000 usuarios únicos y 597.000 páginas vistas. Junto con Puromarketing.com, son los dos portales de entre estos cuatro que presentan una tendencia creciente, mientras que Marketingnews.es y Anuncios.com descienden

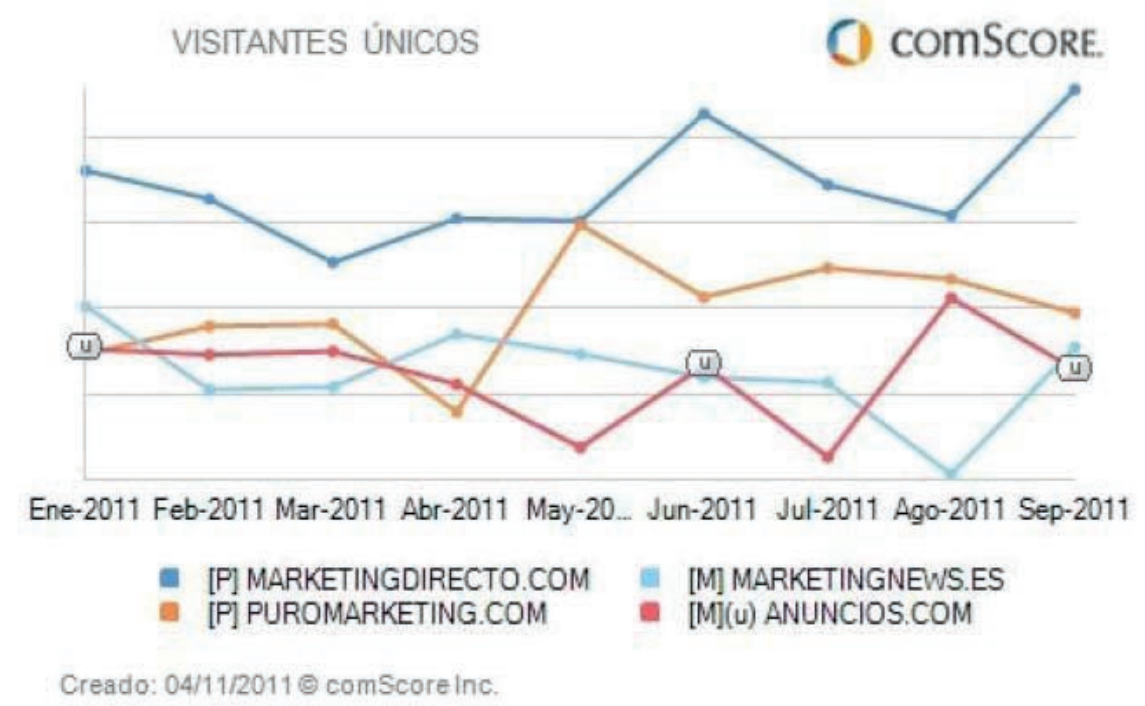

Figura 4. Evolución de visitantes únicos de portales verticales de marketing, comunicación y publicidad

En el caso de los resultados del buscador Google para cada portal, destacan también MarketingDirecto.com y Puromarketing.com como los portales más populares y referenciados: 
Tabla 2. Resultados en Google para la búsqueda entrecomillada del dominio del portal

\begin{tabular}{|l|l|c|}
\cline { 2 - 3 } \multicolumn{1}{c|}{} & \multicolumn{1}{c|}{ Portal } & Resultados en Google para la url del site \\
\hline 1 & Adlatina.com & 235 \\
\hline 2 & Anuncios.com & 66 \\
\hline 3 & Eloublicista.es & 24 \\
\hline 4 & Estrategias.com & 23 \\
\hline 5 & Foromarketing.com & 17 \\
\hline 6 & Icemd.com & 39 \\
\hline 7 & InteractivaDigital.com & 98 \\
\hline 8 & Inmark.com & 117 \\
\hline 9 & Latinsots.com & 439 \\
\hline 10 & Leadingnewthinking.com & 36 \\
\hline 11 & MarketingComunidad.com & 96 \\
\hline 12 & MarketingDirecto.com & 20.600 \\
\hline 13 & Marketingmasventas.wke.es & 6 \\
\hline 14 & MarketingNews.es & 172 \\
\hline 15 & Marketingvcomercio.com & 2 \\
\hline 16 & Maspublicidadvmarketing.com & 9 \\
\hline 17 & MediosvMarketing.es & 25 \\
\hline 18 & Noticom.es & 5 \\
\hline 19 & Periodicopublicidad.com & 50 \\
\hline 20 & Portaloublicitario.com & 17 \\
\hline 21 & Prnoticias.com & 348 \\
\hline 22 & Programapublicidad.com & 52 \\
\hline 23 & Puromarketing.com & 17.200 \\
\hline 24 & Theslogan.com & 230 \\
\hline 25 & Solomarketing.es & 274 \\
\hline 26 & Yorokobu.es & 592 \\
\hline & & \\
\hline
\end{tabular}

Por otra parte, al realizar la búsqueda en Google de las palabras clave "noticias marketing", "noticias comunicación" y "noticias publicidad", nos encontramos con que las primeras posiciones de los resultados naturales (es decir, se excluyen los enlaces patrocinados) están ocupadas por los siguientes portales:

a)

Noticias

marketing:

Marketingnews.es, Puromarketing.com y Marketingdirecto.com.

b)

Noticias

comunicación:

Noticom.es, Prnoticias.com y Elconfidencial.com.

c)

Noticias

publicidad:

Marketingdirecto.com, Puromarketing.com y Maspublicidadymarketing.com.

Por último, en el siguiente cuadro se incluyen los resultados de los portales de la muestra inicial en la clasificación del ranking Alexa y su pagerank: 
Tabla 3. Clasificación en el ranking de Alexa y pagerank

\begin{tabular}{|c|c|c|c|}
\hline & Portal & Clasificación Ranking Alexa & PageRank \\
\hline 1 & Adlatina.com & 58.595 & 05-oct \\
\hline 2 & Anuncios.com & 82.764 & 05-oct \\
\hline 3 & Elpublicista.es & 224.554 & 05-oct \\
\hline 4 & Estrategias.com & 418.515 & 05-oct \\
\hline 5 & Foromarketing.com & 737.013 & 05-oct \\
\hline 6 & Icemd.com & 93.227 & 05-oct \\
\hline 7 & InteractivaDigital.com & 192.082 & 05-oct \\
\hline 8 & Ipmark.com & 208.510 & 05-oct \\
\hline 9 & Latinspots.com & 265.723 & 05-oct \\
\hline 10 & Leadingnewthinking.com & 782.637 & 04-oct \\
\hline 11 & MarketingComunidad.com & 123.969 & 05-oct \\
\hline 12 & MarketingDirecto.com & 9.306 & 06-oct \\
\hline 13 & Marketingmasventas.wke.es & 230.137 & 04-oct \\
\hline 14 & MarketingNews.es & 52.686 & 05-oct \\
\hline 15 & Marketingycomercio.com & 1.194 .102 & 04-oct \\
\hline 16 & Maspublicidadymarketing.com & 901.593 & 04-oct \\
\hline 17 & MediosyMarketing.es & 277.267 & 04-oct \\
\hline 18 & Noticom.es & 5.583 .973 & 04-oct \\
\hline 19 & Periodicopublicidad.com & 188.853 & 05-oct \\
\hline 20 & Portalpublicitario.com & 972.979 & 04-oct \\
\hline 21 & Prnoticias.com & 21.437 & 06-oct \\
\hline 22 & Programapublicidad.com & 300.645 & 04-oct \\
\hline 23 & Puromarketing.com & 7.845 & 05-oct \\
\hline 24 & Solomarketing.es & 182.820 & 03-oct \\
\hline 25 & Theslogan.com & 62.888 & 04-oct \\
\hline 26 & Yorokobu.es & 39.299 & 05-oct \\
\hline
\end{tabular}

A partir de estas páginas web iniciales y en base a los resultados obtenidos en las variables indicadas, se selecciona la muestra final de portales verticales de marketing, comunicación y publicidad para el estudio, eliminando aquellas páginas que son blogs (como marketing.es o blogmktg.com), aquellas iniciativas no españolas (como maspublicidadymarketing.com, latinspots.com o adlatina.com), las páginas que son comunidades (como por ejemplo leadingnewthinking.com, comunidad virtual de la agencia de medios digital Media Contacts), las webs de escuelas de formación (como es el caso de Icemd.com) y las páginas que, pese a ser de información genérica, han aparecido en alguno de los resultados de las variables anteriores (es el caso de Elconfidencial.com). 
La muestra final queda compuesta por diez portales verticales con los mejores resultados en estas variables: Marketingdirecto.com, Puromarketing.com, Marketingnews.es, Anuncios.com, Prnoticias.com, Yorokobu.es, Ipmark.com, Solomarketing.es, Theslogan.com e Interactivadigital.com. El análisis de la portada de las páginas seleccionadas y de su actividad en sus espacios en las principales redes sociales se realiza entre los días 20 y 21 de diciembre de 2011, controlando los siguientes ítems:

a)

Página web: número de noticias publicadas en portada y tipología, en base a las etiquetas online y offline en función de la temática tratada.

b)

Facebook: número de "me gusta", número de publicaciones en el muro, tipología de publicaciones en base a las etiquetas online y offline, resultados de las publicaciones (número de personas que están hablando de esto ${ }^{22}$, número de "me gusta", número de publicaciones compartidas por usuarios y número de comentarios de usuarios ${ }^{23}$ ), respuestas a comentarios y otros contenidos.

c)

Twitter: número de seguidores y de personas a las que sigue, número de tweets totales y publicados en los días del análisis, número de listas y número de menciones.

d)

Youtube: número de videos totales, número de videos publicados en los días del análisis, reproducciones totales del canal y de los videos publicados, fecha de creación, número de suscriptores al canal y número de comentarios sobre el canal.

Por último, se incluye también el índice SoMeS para los portales de la muestra final. SoMeS es herramienta gratuita que nos permite monitorizar la presencia de una empresa o marca en medios sociales, al medir las incidencias de un término en el buscador Google y en los principales medios sociales.

Cada una de las incidencias del término buscado es valorada y catalogada para poder construir los cuatro índices que se presentan en los resultados en tiempo real: impacto, presencia, conversación e índice SoMeS. El impacto sería la capacidad de la marca de ser encontrada rápidamente por un usuario a través del buscador Google, mientras que la presencia se centra en las acciones de la marca en los medios sociales: grupos o páginas corporativas en redes sociales, canal en plataformas de video digital, número de seguidores o fans, activos digitales (imágenes, videos, contenidos, etc.) que la marca coloca en estos espacios. La conversación se refiere al nivel de las conversaciones sobre las marcas que los usuarios generan en los diferentes blogs, así como a las noticias protagonizadas por ellas (monitorizado a través de Google

\footnotetext{
22 Se trata de una nueva métrica ofrecida por Facebook para las páginas desde octubre de 2011 que se refiere al número de personas que generaron una historia sobre la página en el último mes, en base a los nuevos "me gusta", las veces que se comparte en los muros, los comentarios, las respuestas a preguntas, menciones y check-ins.

23 Distinguimos entre los comentarios publicados por usuarios en las páginas en Facebook de los portales analizados y las publicaciones de la página que han sido compartidas por usuarios
} 
News). Por último, el índice SoMeS sería la agregación de todos los datos obtenidos en los medios sociales analizados.

A partir de estos ítems se realiza el análisis de resultados para afirmar o refutar la hipótesis de partida, según la cual, gracias a la importancia que han adquirido actualmente las plataformas digitales dentro de las estrategias de marketing, comunicación y publicidad, las noticias relacionadas con el marketing digital, la publicidad online y los medios sociales son las que más espacio ocupan tanto en la página web como en los canales en plataformas 2.0 de estos portales.

\section{ANÁLISIS Y DISCUSIÓN}

En la siguiente tabla se muestran los resultados recopilados durante los días del análisis de la página web y los espacios en Facebook, Twitter y Youtube de los portales verticales de marketing, comunicación y publicidad de la muestra seleccionada, así como su valor obtenido en el índice SoMeS:

Tabla 4. Resultados de la página web y los espacios en medios sociales

\begin{tabular}{|c|l|c|c|c|c|c|c|c|c|c|c|c|c|}
\multicolumn{1}{c}{} & \multicolumn{1}{c}{ Página } & \multicolumn{10}{c|}{ Facebook } \\
\hline \multicolumn{1}{c}{ Portal } & 1 & 2 & 3 & 4 & 5 & 6 & 7 & 8 & 9 & 10 & 11 & 12 \\
\hline 1 & Marketingdirecto.com & 24 & 17 & 26.285 & 4 & $01-$ & 637 & 72 & 18 & 23 & 0 & 0 & 0,16 \\
\hline 2 & Puromarketing.com & 72 & 58 & 12.476 & 14 & $07-$ & 374 & 125 & 8,9 & 31 & 8 & 0,57 & 0,38 \\
\hline 3 & Marketingnews.es & 20 & 8 & 2.815 & 2 & $01-$ & 76 & 16 & 8 & 2 & 0 & 0 & 0,36 \\
\hline 4 & Anuncios.com & 26 & 4 & 2.966 & 3 & $01-$ & 71 & 3 & 1 & 0 & 0 & 0 & 0,03 \\
\hline 5 & Prnoticias.com & 36 & 2 & 3.963 & 5 & $0 / 5$ & 107 & 3 & 0,6 & 0 & 0 & 0 & 0,02 \\
\hline 6 & Yorokobu.es & 22 & 4 & 13.328 & 6 & $01-$ & 765 & 134 & 22 & 59 & 29 & 4,83 & 0,83 \\
\hline 7 & Ipmark.com & 54 & 4 & 53 & 17 & abr- & 13 & 0 & 0 & 0 & 0 & 0 & 0 \\
\hline 8 & Solomarketing.es & 52 & 41 & 2.577 & 1 & $1 / 0$ & 9 & 2 & 2 & 0 & 0 & 0 & 0,08 \\
\hline 9 & Theslogan.com & 28 & 16 & 5.229 & 0 & 0 & 48 & 0 & 0 & 0 & 0 & 0 & 0 \\
\hline 10 & Interactivadigital.com & 14 & 14 & 4.172 & 1 & $1 / 0$ & 31 & 0 & 0 & 1 & 1 & 1 & 0,05 \\
\hline
\end{tabular}

\begin{tabular}{|c|c|c|c|c|c|c|c|c|c|c|c|c|c|c|c|c|c|c|}
\hline & \multicolumn{7}{|c|}{ Twitter } & \multicolumn{7}{|c|}{ Youtube } & \multicolumn{4}{|c|}{ SoMeS } \\
\hline Portal & 13 & 14 & 15 & 16 & 17 & 18 & 19 & 20 & 21 & 22 & 23 & 24 & 25 & 26 & 27 & 28 & 29 & 30 \\
\hline Marketingdirecto.com & 58 & 56.535 & 0 & 18.631 & 68 & 3.386 & 11 & 245 & 1 & 137.094 & \begin{tabular}{|l|}
3.461 .907 \\
\end{tabular} & $25 / 02 / 2007$ & 5.897 & 86 & 5 & 6 & 2 & 4 \\
\hline Puromarketing.com & 28.724 & 83.769 & $34^{0,}$ & 11.760 & 35 & 4.369 & 14 & 34 & 0 & $\mathrm{~N} / \mathrm{D}$ & 84.233 & $11 / 07 / 2008$ & 126 & 0 & 4 & 7 & 1 & 4 \\
\hline Marketingnews.es & 3 & 6.423 & 0 & 1.117 & 9 & 627 & 7 & \multicolumn{7}{|c|}{ No tiene canal } & 0 & 6 & 1 & 3 \\
\hline Anuncios.com & 51 & 6.212 & $01^{0,}$ & 1.619 & 5 & 283 & 5 & \multicolumn{7}{|c|}{ No tiene canal } & 0 & 10 & 10 & 8 \\
\hline Prnoticias.com & 1.966 & 17.107 & $11^{0,}$ & 15.410 & 83 & 1.058 & 4 & 3.862 & 1 & $\mathrm{~N} / \mathrm{D}$ & 4.230 .774 & $18 / 01 / 2007$ & 1.121 & 0 & 0 & 5 & 3 & 3 \\
\hline Yorokobu.es & 1.008 & 15.123 & $\begin{array}{c}0, \\
07\end{array}$ & 5.435 & 27 & 1.137 & 9 & \multicolumn{7}{|c|}{ No tiene canal } & 0 & 3 & 0 & 1 \\
\hline Ipmark.com & 105 & 724 & $15^{0,}$ & 605 & 9 & 41 & 8 & \multicolumn{7}{|c|}{ No tiene canal } & 0 & 1 & 0 & 0 \\
\hline Solomarketing.es & 279 & 405 & $\begin{array}{c}0 \\
69\end{array}$ & 643 & 12 & 28 & 1 & 13 & 0 & $\mathrm{~N} / \mathrm{D}$ & 6.686 & $16 / 04 / 2011$ & 2 & 0 & 0 & 1 & 0 & 0 \\
\hline
\end{tabular}




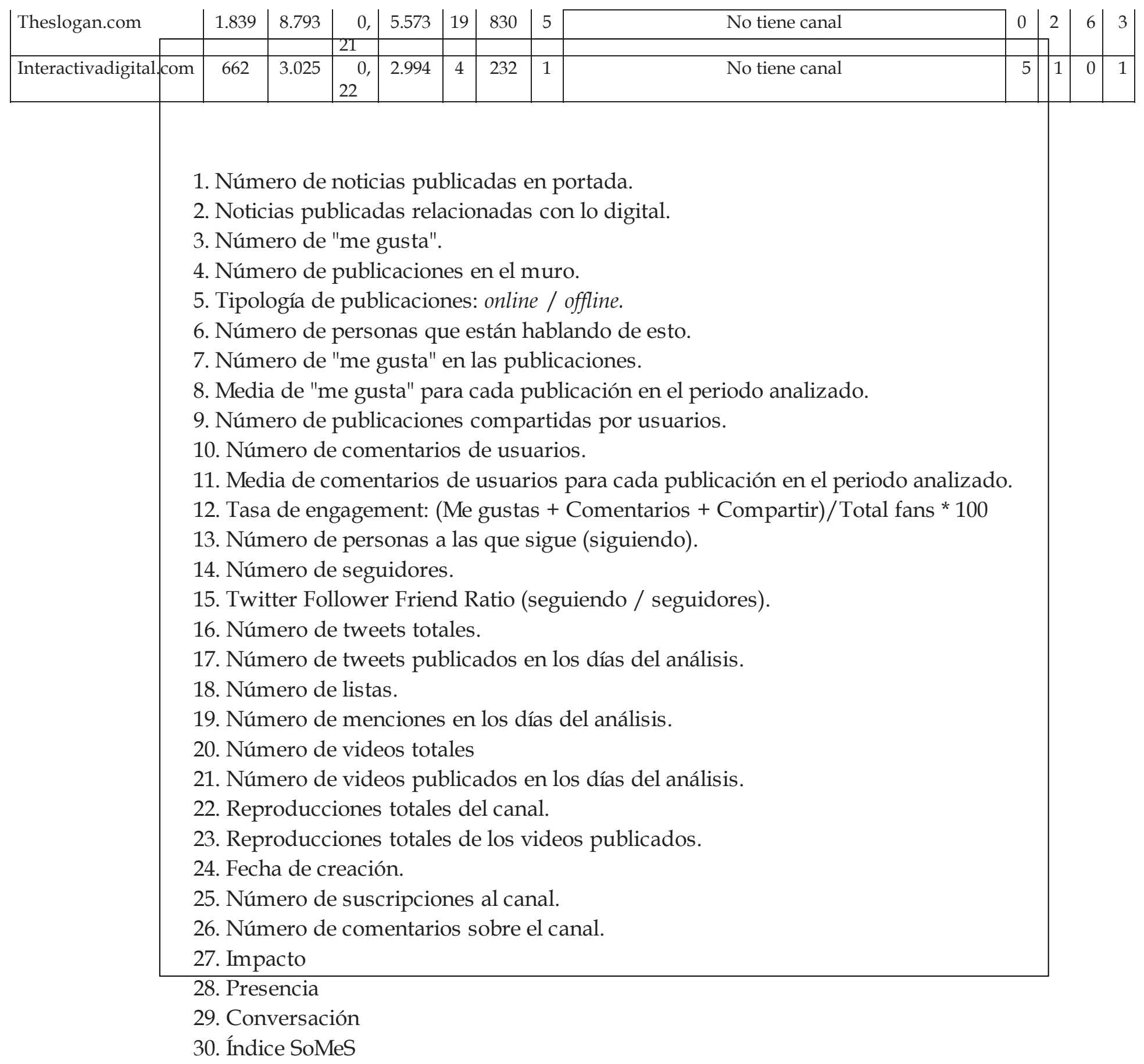

Con respecto a la página web, los diez portales verticales suman durante dos días un total de 349 noticias publicadas en portada (175 diarias), lo que supone una media de 35 noticias para cada portal. Por encima de esa media se encuentran los portales Puromarketing.com (72 noticias), Ipmark.com (54 noticias), Solomarketing.es (52 noticias) y Prnoticias.com (36 noticias), mientras que otras páginas como Interactivadigital.com no superan las veinte noticias. Estas diferencias se deben a la estructura y el diseño de la homepage, que difiere entre unos portales y otros en cuanto al número de noticias que incluyen en su página principal. En el ratio de noticias dedicadas a temáticas relacionadas con lo digital/online destacan los portales Interactivadigital.com (con el 100\% de sus noticias dedicadas a temas relacionados con 
el marketing digital y la publicidad online), Puromarketing.com (con 58 noticias que representan el $80,6 \%$ del total), Solomarketing.es (con el 78,8\%) y Marketingdirecto.com (con el 70,8\%). Todos los portales incluyen en sus portadas noticias del ámbito digital, siendo los porcentajes más bajos los de Prnoticias.com (5,6\%), Ipmark.com (7,4\%) y Anuncios.com (15,4\%). Por ejemplo, en Marketingdirecto.com las dos noticias más destacadas en portada los dos días del análisis, ocupando mayor espacio y apareciendo en las primeras posiciones, están relacionadas con el ámbito digital, al referirse a tendencias tecnológicas y aplicaciones para el móvil creadas por las marcas, entre otros.

A modo de ejemplo, incluimos los titulares de algunas noticias publicadas en las portadas:

- Puromarketing.com: “Vocabulario y términos que todo Community Manager debería conocer", "¡Quiero un buen Community Manager! Claves para reconocerlo", "Tendencias y hábitos del marketing online navideño", "El nuevo Community Manager: preactivos, innovadores y arcanos del conocimiento", "Social Media Marketing para el 2012: ser influyentes es una buena inversión” y "¡Quiero ser influyente en Twitter! Acciones para aumentar nuestros retweets":

a)

Solomarketing.es: “Twitter lanza sus propias páginas de empresa", "Marketing de contenidos, redes sociales o blogs, el eterno debate" y "Las redes sociales, las palabras más buscadas en Google".

b)

Theslogan.com: "Google+: ¿la nueva reina de las redes sociales para las empresas?”, “¿Quieres formarte en marketing online?", “Cómo generar súper fans en Facebook" y “Las 5 R’s de la gestión de crisis en social media".

En el análisis de las páginas web también se han revisado las categorías de noticias que los portales de la muestra incluyen: seis de los diez portales cuentan con categorías dedicadas íntegramente al ámbito digital: Marketingdirecto.com (dentro de la categoría actualidad, cuenta con las secciones digital, e-mail marketing y social media marketing), Puromarketing (en sus categorías principales la primera es marketing digital), Prnoticias.com (con la categoría Internet y redes sociales), Ipmark.com (con la sección marketing interactivo), Solomarketing.es (con las categorías social media e e-mail marketing) y Theslogan.com (con el apartado social media).

Por último, dentro de las páginas web también se ha revisado, como antecedente al análisis de la presencia de los portales en medios sociales, la integración de las plataformas sociales en la página web. Todos los portales analizados cuentan con enlaces a sus espacios en redes sociales, principalmente Facebook y Twitter, desde sus portadas, incluyendo las fanbox de Facebook o la caja de actividad en Twitter. De hecho, ocho de los diez portales analizados incluyen iconos de diferentes medios 
sociales en su cabecera con enlaces a sus espacios en estas plataformas, como puede verse en el cuadro 9:

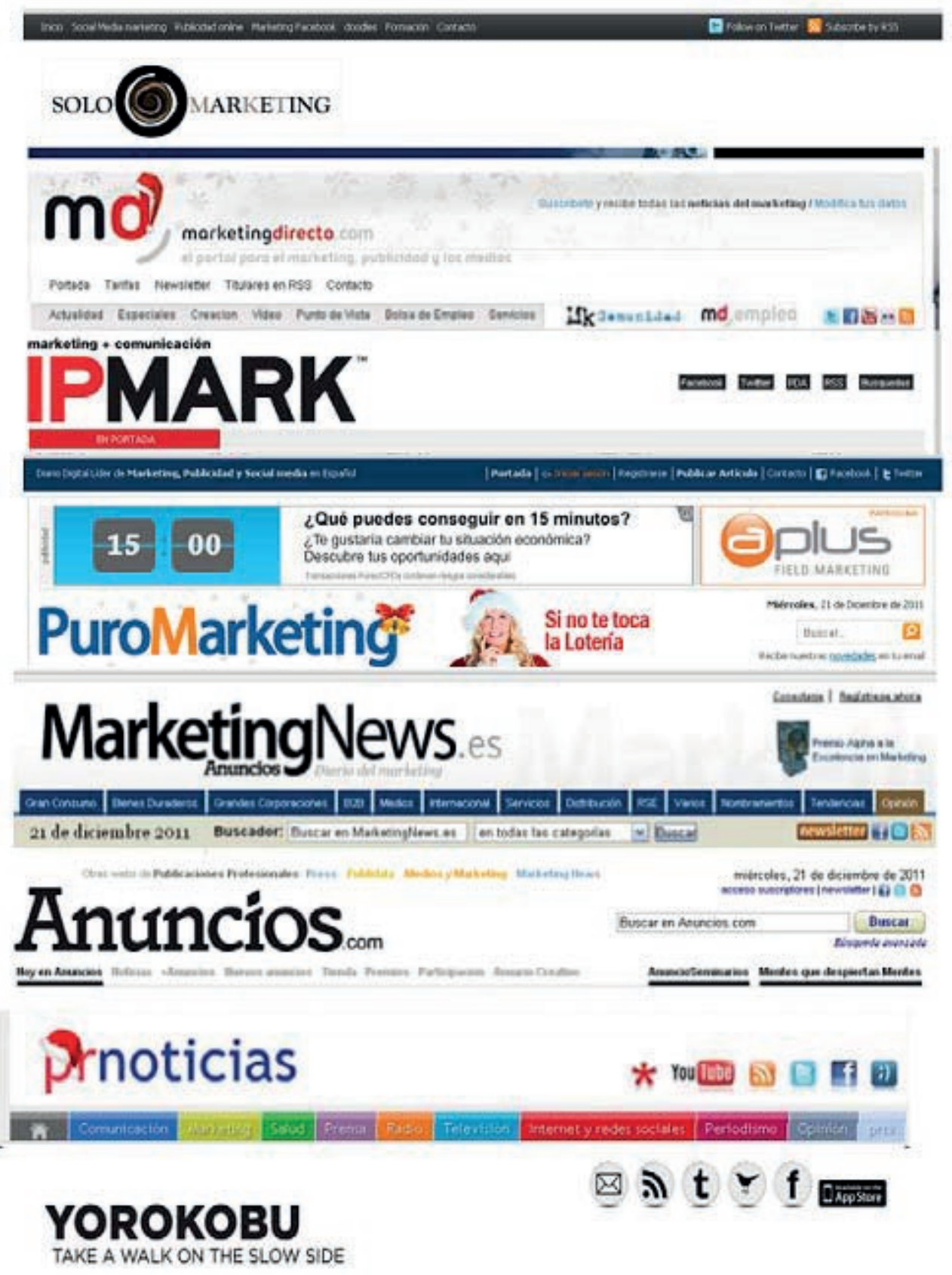

Figura 5. Integración de los medios sociales en las cabeceras de los portales

Además, todos los portales analizados ofrecen al usuario la posibilidad de compartir los contenidos cuando se pincha en el cuerpo de la noticia, con botones de diversas plataformas sociales al inicio o al final del texto: Facebook, Twitter, LinkedIn, Google+, Delicious, Meneame, Xing, Tuenti, Tumblr, Digg o Reddit. 
Pasando al análisis de los datos relativos a Facebook, Twitter y Youtube, todos los portales analizados cuentan con presencia en las dos primeras redes, mientras que en la plataforma de videos digitales tan sólo están presentes cuatro (Marketingdirecto.com, Puromarketing.com, Prnoticias.com y Solomarketing.es). En

general, en cuanto a número de "me gusta" (fans) en Facebook y seguidores en Twitter, los portales tienen más popularidad en la red de microblogging, a excepción de Interactivadigital.com y Solomarketing.es, que tienen más fans en Facebook que seguidores en Twitter, como puede verse en el siguiente cuadro:

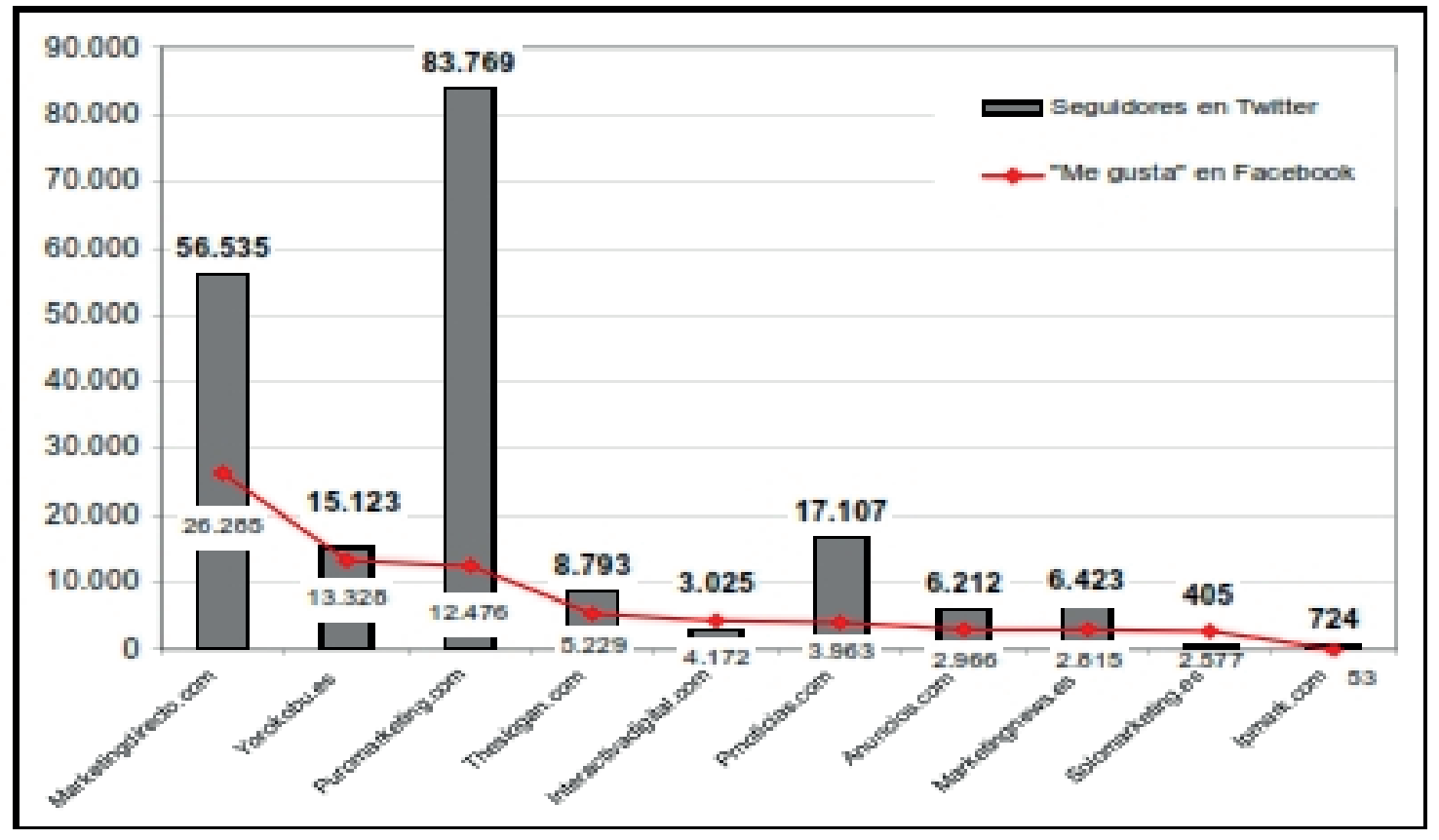

Figura 6. Número seguidores en Twitter y de“me gusta" en Facebook

En el caso de Facebook, los diez portales analizados suman un total de 73,864 "me gusta"; Ipmark.com tiene el espacio en Facebook con menos fans (53) y Marketingdirecto.com es el portal más popular en la red social, con 26.285 "me gusta". Junto con este portal, tan sólo Yorokobu.es (13.328) y Puromarketing.com (12.476) superan la media de "me gusta".

Con respecto a las publicaciones, los diez portales han publicado un total de 53 posts en los dos días del análisis, lo que supone una media por portal de 5,3. Los portales que más publican son Ipmark.com (17) y Puromarketing.com (14); el resto no alcanza las diez publicaciones e incluso Theslogan.com no tienen ninguna en los dos días analizados. El 32\% de las publicaciones estuvo referido a temáticas del ámbito digital del marketing, la comunicación y la publicidad. 

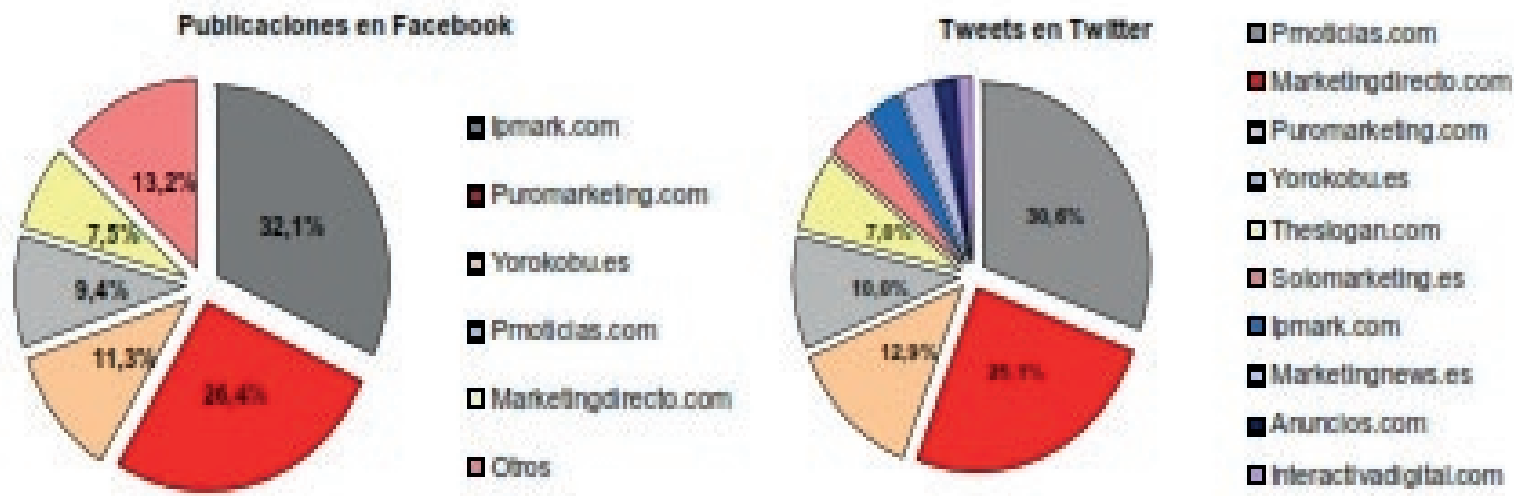

Figura 7. Número de publicaciones en Facebook y tweets en Twitter los días del análisis

Pese a no ser el espacio con más publicaciones en los días del análisis (ocupa la tercera posición con seis publicaciones), en los resultados de las publicaciones en el muro destaca el espacio en Facebook de Yorokobu.es, por ser el que obtiene los valores más elevados en número de personas que están hablando de esto (765), número de "me gusta" en las publicaciones (134), media de "me gusta" para cada publicación (22), número de publicaciones compartidas por usuarios (59), número de comentarios de usuarios (29), media de comentarios de usuarios para cada publicación (29) y tasa de engagement $(0,83)$, como muestran los ítems del 6 al 12 del cuadro 8.

La tasa de engagement de todos los portales es baja, al no alcanzar en ningún caso el valor 1, siendo las más elevadas, tras Yorokobu.es, las tasas de Puromarketing.com $(0,38)$, Marketingnews.es $(0,36)$ y Marketingdirecto.com $(0,16)$. El resto de portales no llegan en este ítem al 0,1.

En total, los diez portales verticales suman en dos días 2.131 personas hablando de esto y 509 interacciones de usuarios ("me gusta", comentarios y publicaciones compartidas). Tras Yorokobu.es, destacan los espacios de Marketingdirecto.com y Puromarketing.com por el número de personas que están hablando de esto, "me gusta" y publicaciones compartidas, aunque cuentan con valores bajos o incluso negativos (en el caso de Marketingdirecto.com) para los comentarios.

Es decir, los usuarios interactúan al pinchar en "me gusta" y compartir, pero no comentan los contenidos.

Este hecho puede que se deba, en parte, a la estructura que suelen seguir los portales a la hora de publicar contenidos, resultado muchas veces de automatizar la publicación en Facebook de las noticias que difunden en sus páginas web.

Los posts suelen tener como título el titular de la noticia, ir en ocasiones acompañados por una imagen de la noticia y un fragmento del cuerpo de texto: 

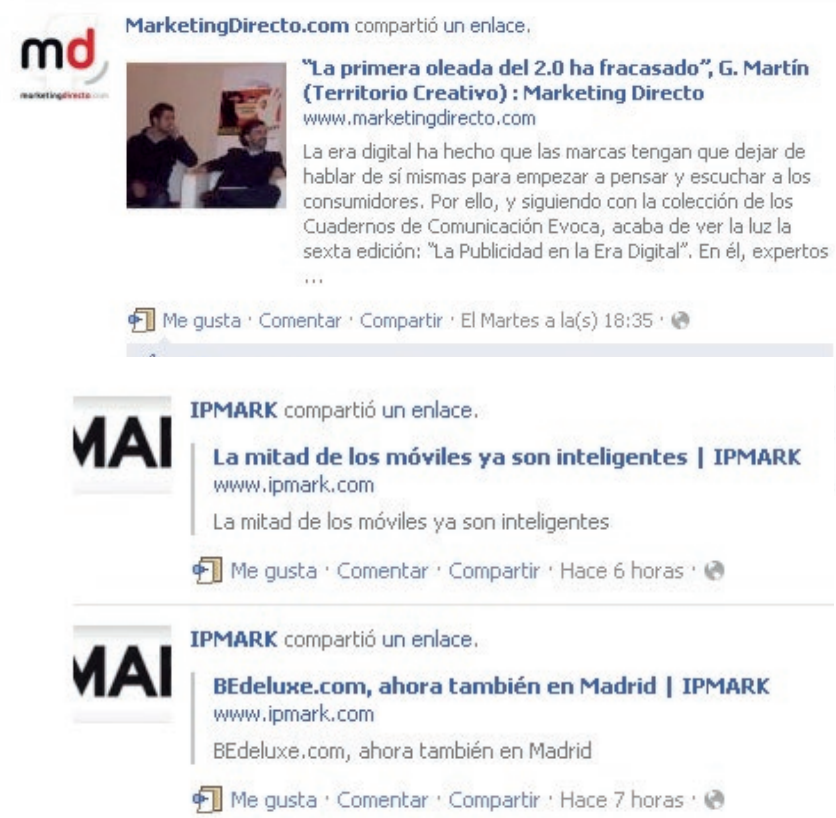

Figura 7. Estructura de los posts en Facebook de Marketingdirecto.com e Ipmark

Esta estructura es la que siguen en sus publicaciones en Facebook prácticamente todos los portales; sólo en el caso de Prnoticias.com se realizan preguntas a usuarios para generar más interés sobre el tema tratado y/o fomentar la interacción y la participación del usuario, si bien incluso formulando cuestiones a los usuarios las publicaciones tampoco en este caso obtienen comentarios de los usuarios:

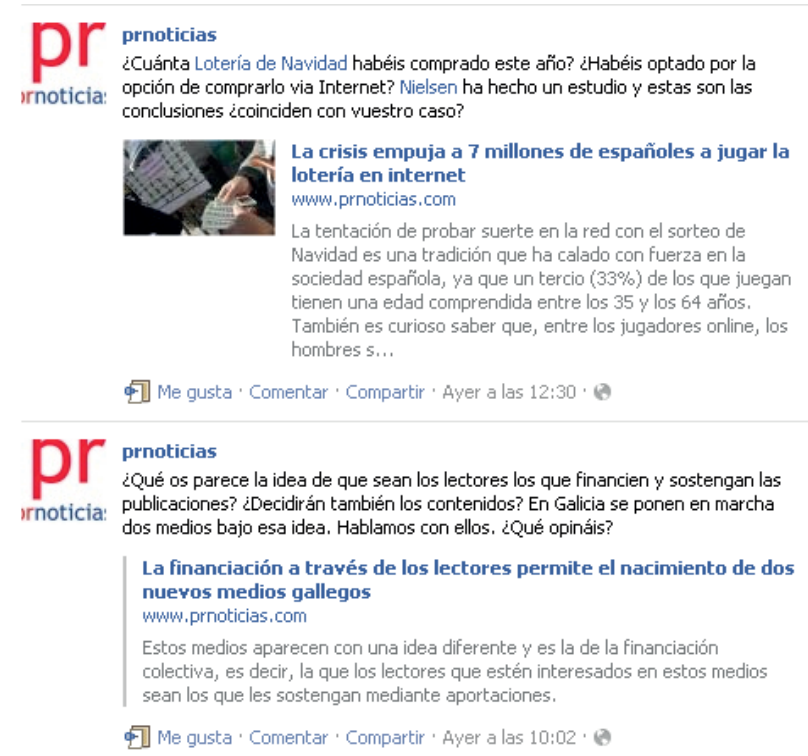

Figura 8. Preguntas a usuarios en las publicaciones en Facebook de Prnoticias

Pasando a comentar los datos relativos a la red de microblogging Twitter, en total los diez portales están siguiendo a más de 34.500 usuarios en este espacio, destacando a gran distancia Puromarketing.com, que sigue a 28.724 twitteros. Prnoticias.com, 
Theslogan.com y Yorokobu.es cuentan en este valor con cifras entre 1.000 y 2.000 usuarios a los que siguen mientras que portales como Marketingdirecto.com, Anuncios.com y Marketingnews.es siguen a pocas personas (58, 51 y 3, respectivamente.

En este sentido, también es interesante tener en cuenta el Twitter Follower Friend Ratio (TFFR), que pone en relación las personas a las que sigue el portal con el número de individuos que le siguen. Si el TFFR es inferior a uno, significará que esa cuenta está siguiendo a más personas de las que le siguen, mientras que superar el uno implicará que tiene más usuarios que le siguen que personas a las que sigue. Por ejemplo, mientras que Markeringnews.es tan sólo sigue a 3 personas, le siguen 6.423 twitteros, lo cual supone un TFFR de 0. Ninguno de los portales analizados alcanza en este ratio el valor de 1, por lo que todos tienen más seguidores que personas a las que siguen (la media de TFFR para la muestra es de 0,18). Solomarketing.es y Puromarketing.com son los que tienen los valores más cercanos al uno, con 0,69 y 0,34 , respectivamente.

Observando los datos de la columna 14 (seguidores de las cuentas de los portales verticales en Twitter), los diez portales suman 198.116 seguidores; de nuevo Puromarketing.com destaca con la cifra más alta (83.769), seguido de Marketingdirecto.com (56.535). La columna 18 aporta información sobre las listas en las que los usuarios han incluido a los portales para realizar un mayor seguimiento de su actividad en Twitter. En general, en este valor los portales analizados también son muy populares, al sumar 11.991 listas y superar en varios casos (40\%) más del millar: Puromarketing.com (4.369 listas), Marketingdirecto.com (3.386 listas), Yorokobu.es (1.137 listas) y Prnoticias.com (1.058 listas).

Como vemos en la columna 16, estos portales han publicado en sus cuentas de Twitter desde el inicio de su actividad 63.787 tweets (media de 6.378 tweets por portal). Los portales que tienen mayor actividad son Marketingdirecto.com (con 18.631 tweets) y Prnoticias.com (con 15.410 tweets). Estos portales son también los que más tweets publican en los días del análisis (Prnoticias.com con 83 y Marketingdirecto.com con 68). La media de tweets publicados en los días del análisis es de 27 por portal, por lo que además de los dos anteriores otros dos portales alcanzan este valor: Puromarketing.com, con 35 tweets, y Yorokobu, con 27 tweets

En el caso de la estructura de los tweets, observamos la misma tendencia que en la red social Facebook: las noticias se publican de manera automatizada a partir de las que se publican en la página web y cuentan con el titular de la noticia y una url acortada dado el límite de 140 caracteres que tienen los tweets que enlaza a la noticia completa, generando así tráfico a la página web del portal vertical. En la mayoría de casos no se 
utilizan hashtags ${ }^{24}$ para categorizar la noticia; únicamente dos de los diez portales los usan (Ipmark.com y Solomarketing.es):

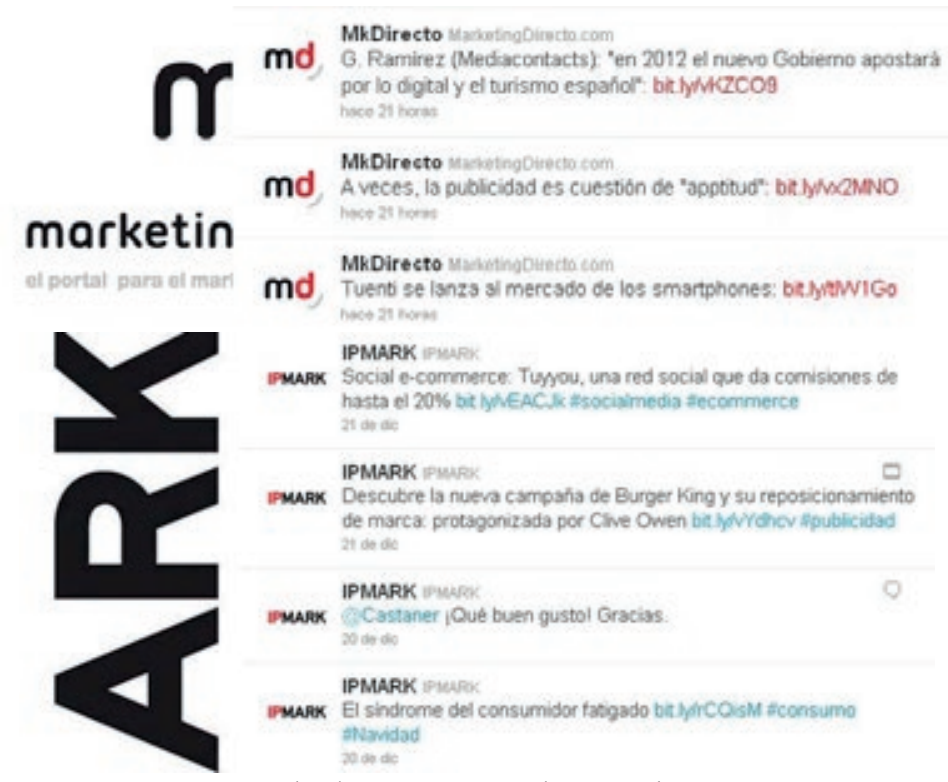

Figura 9. Estructura de los tweets de @MkDirecto y @IPMARK

El último ítem analizado de Twitter (número de menciones en los días del análisis, en la columna 19), presenta valores bajos, por lo que al igual que ocurría en Facebook con los comentarios en este caso el usuario tampoco interactúa demasiado ni genera conversación con el portal utilizando la mención, es decir, incluyendo en un tweet el nombre de cuenta del portal precedido por @ (por ejemplo @IPMARK) para indicar que ese mensaje va dirigido a esa cuenta o el usuario quiere que lo lea.

Frente a los 271 tweets publicados en los días del análisis, en total los diez portales suman 65 menciones, por lo que si calculamos el ratio menciones/tweets no alcaza el $1(0,24)$. Este dato muestra la poca difusión que los usuarios hacen de las noticias publicadas por los portales verticales en Twitter, relacionada también por la estructura de los mensajes que acabamos de comentar. En general, los portales que más tweets publican son los que tienen un ratio menciones/tweets más bajo (como sucede con Marketingdirecto.com y Prnoticias.com), mientras que cuentas que publican pocos tweets obtienen un ratio más elevado, aunque no superan el 1 (Anuncios.com con un ratio de 1 y cinco tweets, Ipmark.com con un ratio de 0,89 y nueve tweets y Marketingnews.es con un ratio de 0,78 y nueve tweets).

Con respecto a la presencia en la plataforma de videos digitales Youtube, el $40 \%$ de los portales verticales cuenta con un canal propio: Prnoticias.com y

\footnotetext{
${ }^{24}$ Los hashtags son las palabras incluidas en los mensajes en Twitter (tweets) que van acompañadas por el símbolo \#, usadas como etiquetas para agrupar y organizar contenidos que hablen sobre una misma temática, evento o noticia
} 
Marketingdirecto.com destacan como las cuentas más consolidadas, al ser creadas en ambos casos a primeros de 2007 y tener el mayor número de videos totales (3.862 y 245 , respectivamente), reproducciones totales de los videos (4.230.774 y 3.461.907, respectivamente), videos publicados en los días del análisis (un video cada uno) y suscripciones (1.121 y 5.897, respectivamente).

Los otros dos portales con presencia en Youtube (Puromarketing.com y Solomarketing.es) no parecen publicar en esta plataforma de manera demasiado continuada, al tener desde su creación pocos videos publicados, no haber publicado ninguno en los días analizados y no contar con un elevado número de personas suscritas al canal.

Por último, si nos fijamos en el índice SoMeS el portal con un valor más elevado es Anuncios.com, con un índice de 7,8, seguido por Marketingdirecto.com $(4,2)$ y Puromarketing $(4,0)$. El resto de portales obtienen valores bajos que no alcanzan los cuatro puntos. Estos portales son también los que adquieren los valores más elevados en presencia, parámetro de medición basado en las acciones de la marca/empresa en medios sociales.

Es curioso también que en el valor impacto de este índice únicamente tres portales adquieren puntuación: Marketingdirecto.com (5,3), Interactivadigital.com $(4,6)$ y Puromarketing.com (4,4). El resto tienen un impacto de 0, de acuerdo con la herramienta SoMeS, probablemente debido a los escasos contenidos que pueden encontrarse si se realiza una búsqueda del site en Google. En el parámetro conversación destacan Anuncios.com, con un valor muy elevado $(9,7)$ y Theslogan.com $(6,1)$, pese a tener estas últimas cifras bajas en el resto de indicadores del índice SoMeS. Por tanto, son los portales más populares en cuanto al nivel de conversaciones que generan en los diferentes medios sociales. El resto no alcanzan los 3 puntos e incluso obtienen valores de cero (casos de Ipmark.com y Solomarketing.es, por lo que se entiende que generan escasa o nula conversación entre los usuarios).

Del análisis de todos los datos extraídos podemos afirmar que los portales con más tratamiento de noticias relacionadas con el ámbito digital, con una integración de las noticias para favorecer su difusión en medios sociales y los que más presencia y popularidad tienen en estas plataformas son Marketingdirecto.com y Puromarketing.com aunque en general podemos afirmar que todos los portales analizados conceden importancia en sus contenidos al marketing digital, la publicidad online y los medios sociales, son conscientes de la importancia de tener presencia en medios sociales y conectar sus contenidos con estas plataformas y tienen una presencia continuada en entornos 2.0.

Sin embargo, y pese a contar todos los portales analizados, como hemos visto, con integraciones de las plataformas sociales en sus páginas web, su presencia en medios sociales está basada principalmente en difundir noticias de manera automatizada para generar tráfico a la página web, más teniendo en cuenta el interés que genera 
hoy en día entre los usuarios todo lo relacionado con el marketing digital, sin generar demasiada interacción con los usuarios ni motivar la conversación. Pruebas de ello son las pocas menciones en Twitter y los escasos comentarios que reciben las publicaciones en Facebook, derivados del tono de noticias que tienen los mensajes emitidos por los portales, sin formular preguntas que conecten con el usuario o fomenten su participación, o el TFFR, con valores muy bajos que indican que estos portales siguen a muy pocos usuarios si lo comparamos con los usuarios que les siguen.

\section{CONCLUSIONES}

A partir de los resultados mostrados en el apartado anterior y de la investigación documental analizada, podemos afirmar que las noticias relacionadas con el marketing digital, la publicidad online y los medios sociales son, en general, las más populares en los portales verticales de marketing, comunicación y publicidad, dados el interés por el ámbito empresarial en incluir las plataformas 2.0 en sus estrategias y la actualidad de la temática. Igualmente, se observa una elevada popularidad de estos portales verticales entre los usuarios de medios sociales, con alto grado de seguimiento en espacios como Facebook o Twitter. Por tanto, podemos aceptar la hipótesis de partida, a partir de los resultados extraídos en el análisis.

En el entorno del marketing 3.0 (Kotler, p. 2010), en el que el cambio radica en cómo las estrategias empresariales pasan de centrarse en el cliente a enfocarse a la persona, las redes sociales representan espacios de conversación sobre temáticas como las propias marcas e instituciones. De ahí la importancia de ser transparentes en medios sociales y satisfacer las demandas y deseos del consumidor, en un enfoque clienterelación:

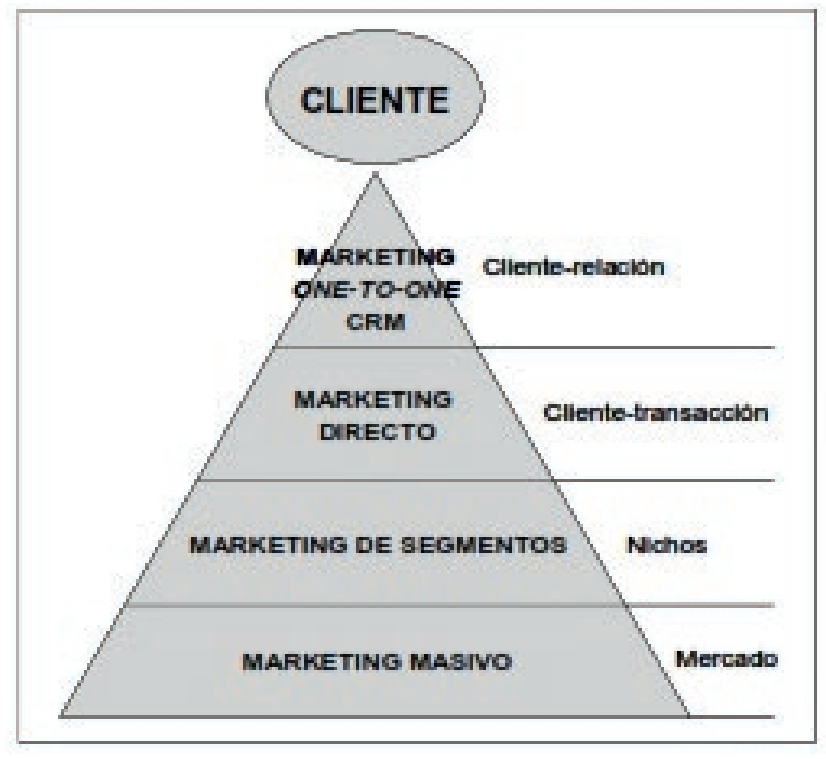

Figura 10. La orientación de marketing Elaboración propia a partir de Cuesta Fernández, 2003, p. 24 
Los portales verticales de marketing, comunicación y publicidad se han retroalimentado de este cambio de enfoque empresarial, directamente relacionado con las áreas de marketing, comunicación y publicidad, y hoy en día centran su atención en el amplio abanico de temáticas que engloban las plataformas 2.0 aplicadas a estos ámbitos: herramientas para gestionar la reputación online (Online Reputation Management, ORM) y monitorizar los medios sociales, los criterios que conforman la medición del Retorno de la Inversión (ROI) y del impacto en la relación (IOR) en estas plataformas, las funciones de la figura del Community Manager, la geolocalización, el social commerce, el Customer Relationship Managment social (CRM social), las diferentes pantallas digitales (móviles, tablets, etc.) o los hábitos de consumo de medios del usuario basados en el multitasking, entre otros temas.

Del mismo modo, estos espacios también han asumido para sus propias estrategias de generación de tráfico y difusión de noticias el papel que juegan los medios sociales y la viralidad de los usuarios en estos entornos, sobre todo para temas relacionados con el marketing digital, si bien desde nuestro punto de vista es importante que comprendan la filosofía 2.0 que debe imperar en los contenidos que se publican en estos espacios, implicando y teniendo en cuenta al usuario para fomentar su participación.

Posibles futuras líneas de investigación relacionadas con la temática de este estudio se centrarían en conocer la gestión interna de la comunicación en los espacios 2.0 a través de la figura del Community Manager, en revisar la evolución de las noticias tratadas en función de la importancia que adquieren nuevas tendencias en las estrategias empresariales y el marketing digital o en analizar la opinión de los profesionales del sector con respecto a estos portales verticales de marketing, comunicación y publicidad como fuentes de información.

\section{REFERENCIAS}

Alonso Coto, M. A. (2008). El plan de marketing digital: Blended Marketing como intergración de acciones on y offline. Madrid: Pearson Education.

Bermejo Berros, J.(2008). El receptor publicitario del siglo XXI en el marco de la interactividad: entre el consumer y el prosumer. En Pacheco Rueda, M. (Eds.). La publicidad en el contexto digital. Comunicación Social. Sevilla, pp. 49-78.

Bryant, J. \& Miron, D. (2004). Theory and Research in Mass Communication. Journal of Communication, 54, (4), 662-704.

Castelló Martínez, A. (2010). Estrategias empresariales en la Web 2.0. Las redes sociales online. Alicante: Editorial Ecu.

Celaya, J. (2008): La empresa en la Web 2.0. Madrid: Gestión 2000.

Cuesta Fernández, F. (2003).Fidelización: Un paso más allá de la retención. Madrid: McGraw-Hill. 
De Salas Nestares, M. I. (2002). La comunicación empresarial a través de Internet.. Valencia: Servicio de publicaciones Universidad CEU-Cardenal Herrera

Fleming, Paul (2000). Hablemos de marketing interactivo. Barcelona: Esic Editorial.

Kotler, P. (2010). Marketing 3.0. From products to costumers to the human spirit New Jersey: John Wiley \& Sons.

Madinabeitia, E. (2010). La publicidad en medios interactivos. En busca de nuevas estrategias. Revista Telos, (82), 43-54. Madrid: Fundación Telefónica. Consultado el 01 de Julio del 2011, de http:/ / sociedadinformacion.fundacion.telefonica.com/DYC/TELOS/SOBRETELOS /Nmerosanteriores/DetalleAnteriores_82TELOS_DOSSIER2/seccion=1268\&idioma $=$ es_ES\&id $=2010020211580001 \&$ activo $=6$. do

Marshall, D. (2004). New Media Cultures. London: Arnold Publishers.

Martí Parreño, J. (2006). Los contenidos publicitarios y el nuevo consumidor de medios digitales: del consumer al prosumer. Consultado el 01 de Julio del 2011, de http://www.cibersociedad.net/congres2006/gts/comunicacio.php?id=259\&llengua $=\mathrm{es}$

ScolarI, C. (2008). Hipermediaciones. Elementos para una teoría de la comunicación digital interactiva. Barcelona Gedisa: Editorial.

Victoria Más, J. S. (Eds.) (2005).Reestructuras del sistema publicitario. Barcelona: Ariel Comunicación.

\section{Araceli Castelló-Martínez}

Profesora Ayudante en la Universidad de Alicante para la asignatura "Introducción a la investigación de medios" y colaboradora en diversos postgrados.Ha impartido docencia también en la Universidad CEU Cardenal Herrera y en la Universidad de Alicante para asignaturas como "Deontología de la Publicidad y las RR.PP." y “Sistemas y Procesos en Publicidad y RR.PP."Doctora en Comunicación por la Universidad Cardenal Herrera-CEU (2009), Magíster en Comunicación Integral por la Universidad Complutense de Madrid (2004) y Licenciada en Publicidad y RR.PP. por la Universidad de Alicante (2003), obteniendo el premio extraordinario de Licenciatura y el Segundo Premio Nacional de Terminación de Estudios Universitarios. 